\title{
Human Aspects of Information Ergonomics
}

\author{
Michael Herczeg and Michael Stein
}

\section{Introduction}

The need for information within a real-time operational environment, e.g. a transportation system, is related to predefined tasks and emerging events as well as the resulting activities and communication processes. Human operators have to perform such tasks and react to such events taking place in their environment. They have to interact and communicate with other humans and machines to fulfill their duties.

Especially in the field of transportation systems, information required by the operator for process control and regulating activities is to an increasing degree no longer perceived directly from the environment (outside view) but collected via sensor systems, processed, enriched with additional information, and communicated by media (Herczeg 2000, 2008, 2010; Stein 2008). Examples of this are head-up displays in which the real view is overlaid with symbols (scenelinked as required), forward looking infrared (FLIR), or also enhanced and synthetic vision systems (e.g. tunnel in the sky) consisting only of a synthetic image including additional information. As compared to the "mere" outside view in combination with "conventional" displays, this shall enable the operator to gain more adequate situational awareness (SA) of the environmental and system status. The workload shall also be optimized and brought to an appropriate level (Nordwall 1995). The ultimate goals are the safe operation of the transportation systems as well as an enhancement of performance.

The media-based communication of information as described is accompanied by an increasing degree of automation (cf. modern aircraft: glass cockpit). In the sense

\author{
M. Herczeg $(\bowtie)$ \\ Institute for Multimedia and Interactive Systems, University of Luebeck, Luebeck, Germany \\ e-mail: herczeg@imis.uni-luebeck.de \\ M. Stein \\ German Air Force Institute of Aviation Medicine, Manching, Germany
}


of cognitive automation (cf. Flemisch 2001) information systems on an information presentation level are intended to enable (partial) congruity between the real process and the cognitive model of the process which is sufficient for the operator to perform the process control tasks successfully (Herczeg 2006b). This generally involves a system complexity which is partially presented in such a way that the cognitive resources of the operator are sufficient. If the system complexity exceeds the cognitive capacity of the operator he will usually respond with cognitive reduction strategies. This means that the operator will consciously or subconsciously choose parts of the complex system (or of a complex information system) which are of lower priority to him compared to other parts and he will eliminate these from his "cognitive model and plan". This can initially reduce the working memory load. However, if such action plans are needed, for instance in cases of emergency or also during phases of high cognitive work load, the operator usually cannot restore and apply these, possibly causing a loss of situation awareness or also a breakdown of communication and action regulation.

The increasing media-based communication of system and control relevant information as described above, combined with a large degree of automation and system complexity, create high demands especially of media-based communication of information. This complex communication patterns require sophisticated information ergonomics, in particular and illustrates the significance of information ergonomics, in particular the importance of modeling cognitive processes which control access to an information system.

This chapter contains an overview of how human operators accomplish these challenges physically and mentally. We will present and discuss some basic cognitive models of human activities and their limits as well as psychological constructs such as motivation, emotion, effort regulation, workload and fatigue.

\section{Cognitive Models for Activities and Communication}

Activity and communication processes have been described in several abstract models by many authors before. Some of these well-known models, which have been successfully used and proved in many application domains, will be described in the following sections. Particular emphasis will be placed on information perception, memorization, and processing as well as the generation of information within these processes.

\subsection{Skills, Rules and Knowledge: Signals, Signs and Symbols}

In accordance with Rasmussen $(1983,1984)$ the problem-solving activities of human operators mainly perform on three different levels of physical and mental capabilities. These levels represent different problem-solving strategies (cf. Fig. 1): 


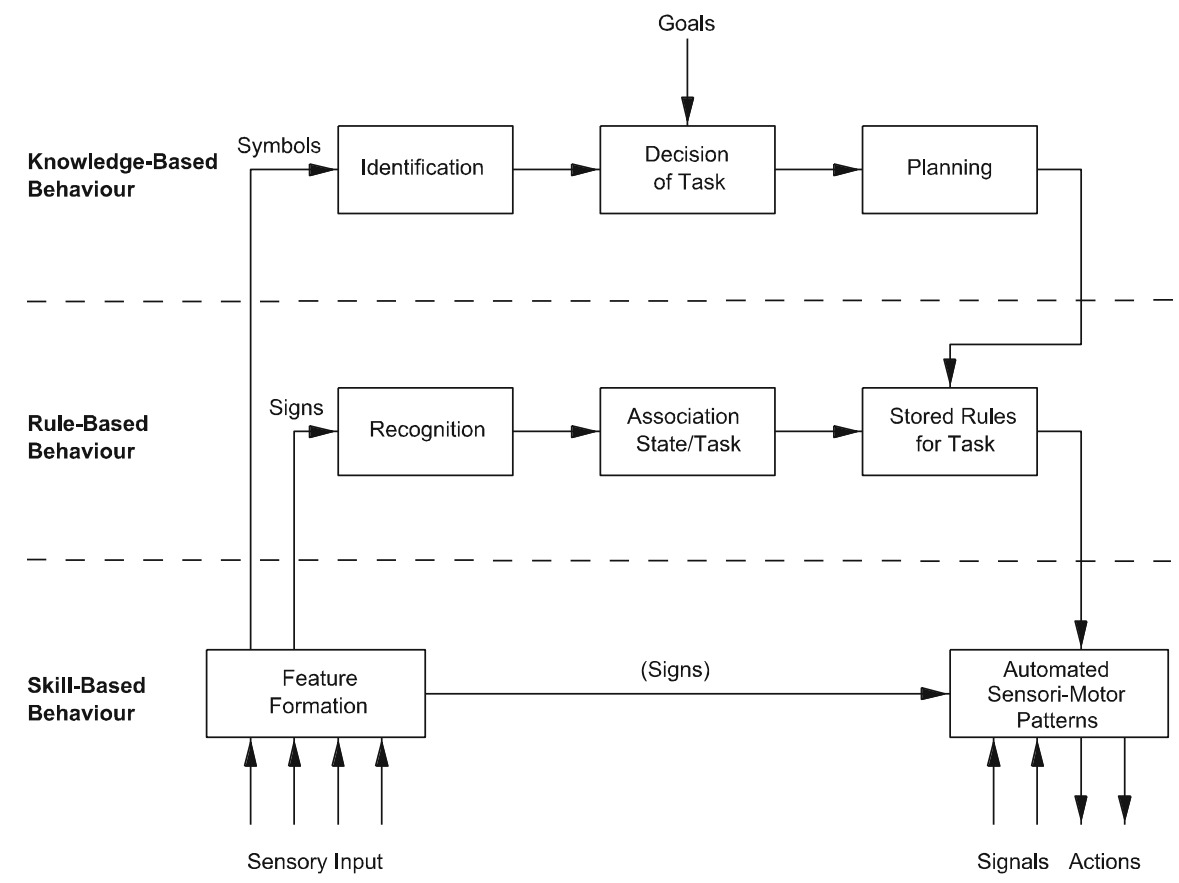

Fig. 1 Levels of problem-solving behaviour (cf. Rasmussen 1983)

1. Skill-Based Behaviour: perceiving events in the environment through signals and reacting with mostly automated sensomotorical procedures;

2. Rule-Based Behaviour: perceiving state changes recognized through signs and reacting with learnt rules;

3. Knowledge-Based Behaviour: perceiving more complex problems through symbols, solving these problems in a goal-oriented way and planning activities to react to the environment.

Rasmussen relates these three forms of behaviour to three forms or qualities of information perceived:

1. Signals: perceived physical patterns (data); e.g. the brake light of a car to inform the following driver about a brake maneuver;

2. Signs: processed signals relating to system states (information); e.g. the fuel indicator with a low-level warning light for the fuel tank of a car;

3. Symbols: processed signs relating to meaningful subjects, objects and situations in the environment (knowledge); e.g. the traffic information about a congestion some distance down the highway.

These three information qualities can be differentiated by specific characteristics. Signals are simple perceptions without meaning. They can trigger automated behaviour, usually stored in the subconscious domains of the human memory. 
This automated behaviour (human skills) is a kind of compiled information supporting pattern recognition and fast reactions. Signs are selectors and triggers for predefined rules. Rules are highly structured knowledge in the form of conditionaction-pairs where the signs are the condition parameters (keys) of the rules. Symbols are semantically rich information, often culturally loaded with various associations to people, objects and situations in the world perceived. They can be viewed as the building blocks of human knowledge (so-called chunks).

Process control systems must be designed in such a way that the information presented corresponds to the cognitive level of problem solving. This means that signals need to be safely discriminated initiating patterns for the precompiled, i.e. trained and memorized subconscious procedures. Signals have to meet a specific information quality, i.e. they:

- Have to be presented with a signal to noise ratio that prevents both alpha-errors (not recognizing the signal) as well as beta-errors (erroneously perceiving a nonexisting signal) (Wickens and Hollands 2000); e.g. the traffic light should not be perceived as being lit due to reflected sunlight;

- Must have a sufficient perceptual distance between one another because they will not be reflected and processed by higher-order knowledge for disambiguation; e.g. the brake light should not be confused with the backlight of a car;

- Should have sensory properties to support neural processing without preceding learning effort, rather than just being arbitrary (Ware 2000, p. 10 ff., Ware calls them "symbols", but refers to low level neuronal processing);

- Have to be presented within a time frame that allows for safe and timely reaction, e.g. the ABS feedback will be haptically fed into the braking motion of the driver's foot instead of providing a light or a warning tone which might be recognized and processed too late into an activity.

While signals support the lowest level of fast and skilled reaction in the sense of a pattern-matching construct, signs have to be interpreted in the context of system states. Certain system states will be preconditions for rules to be triggered. Signs play the role of additional triggering parameters for an operator to change a system state by some activity. Therefore, signs should have the following qualities, i.e. they:

- Should be perceived as system states, not just as perceived patterns; e.g. the oil pressure warning lamp provides the visual indication of an oil can;

- Have to represent certain system properties without ambiguity; the low fuel light should be clearly distinguishable from the low oil indicator;

- They have to be stable to allow a safe rule matching process (Newell and Simon 1972), i.e. enough time to check a potentially long list of rules to find the matching ones; the rule-matching process can be accelerated by preordering or compiling (i.e. changing their representation for efficient matching) rules according to their triggering signs; therefore, signs have an important discriminator function for actions to be taken, which means that they play an important role in structuring state information in the operator's mental models, e.g. there has to be a stable hysteresis for a low fuel light instead of a flickering warning light changing its state depending on the current driving dynamics. 
Whenever there are no matching skill patterns or rules, signs can be processed further loaded with further meaning to be perceived as symbols within a framework of knowledge representation. Symbols can therefore be:

- Larger information structures characterizing a complex situation; e.g. a colored weather radar display showing a larger area in front of the airplane;

- Information bound to scenarios of dynamic problem solving; e.g. a TCAS display presenting not only the collision danger, but the direction to be taken as well;

- Signs related to objects, their relations and meaning, i.e. semiotic structures (Nöth 2000); a fuel tank display in an airplane shows all tanks positioned according the physical structure (layout) of the plane;

- Ambiguous information that has to be discriminated and used within complex contexts, e.g. radar echoes associated with transponder information to filter out irrelevant static objects for an ATC screen.

As a result, symbols cannot just be displayed on a screen. They must emerge as complex perceptual structures related to situations, behaviour, relations, activities, social relationships and even cultural contexts.

\subsection{Layers of Functional Abstraction and Decomposition}

Complex systems and processes with hundreds or even tens of thousands of parameters and multiple interrelations between these parameters cannot be conceived as a whole and cannot be understood on one level of abstraction. Rasmussen (1983, 1985a) proposed an abstraction hierarchy to reflect on several layers of abstraction (cf. Fig. 2) to understand and operate a complex process control system depending on the current context. The abstraction layers defined represent different ways of perceiving and understanding the functions of complex systems:

1. Functional Purpose: This level is related to the ultimate reason why the system has been built and put into operation. For a vehicle it will be its main function of transporting people or payload from one place to another. Typical information related to this level will be, for example, efficiency, time to destination or cost of delivery.

2. Abstract Functions: Looking one level deeper into the functional structure we will find more or less complex topologies of flow. In transport systems we will find for example the complex structure of routes leading from a starting point to a destination. The information needed on this level might be the topological structure and the capacity or the current load of different routes.

3. Generalized Functions: From this point of view we will find concepts like oneway or multilane routes, which are generalizable concepts for routes that can be used by one or more vehicles in the same or opposite directions in parallel or sequentially according to certain traffic modes. 


\section{Functional Purposes}

system objectives

production flow models

Abstract Functions

causal structure

mass, energy and information flow topology

\section{Generalised Functions}

standard functions and processes

control loops

\section{Physical Functions}

electrical, mechanical, chemical processes of components and equipment

\section{Physical Form}

physical appearance and anatomy

material and form

locations

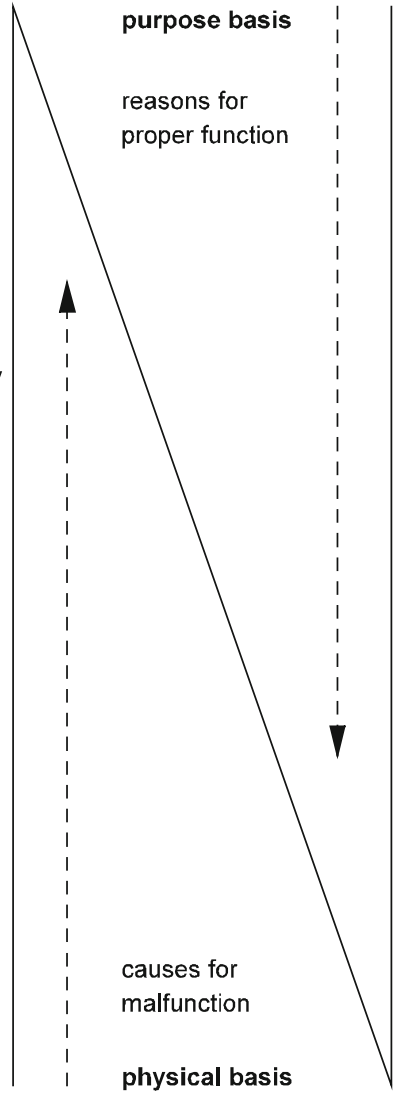

Fig. 2 Levels of abstraction for process control (cf. Rasmussen 1983)

4. Physical Functions: This level tries to map the general functions to a specific physical modality. A route for a ship will be a surface waterway, while a route for an airplane will be a 3D trajectory in the air. While it may make no difference to calculate time to destination on the level of generalized functions, the physical medium must be taken into account for calculations on this physical level.

5. Physical Form: The lowest level of abstraction deals with the final physicality of a process element. This might be, for example, the form, size and physical state of a road or the weather conditions of a selected flight level. Information on the physical level will be naturally perceived by multiple human senses. To give an operator access to this level he or she needs to be connected to the physical situation by multimodal perceptual channels, for instance visual, auditory or tactile senses (Herczeg 2010).

With respect to information ergonomics these abstraction layers can be used to provide a goal-oriented and problem-specific view of the process for different 


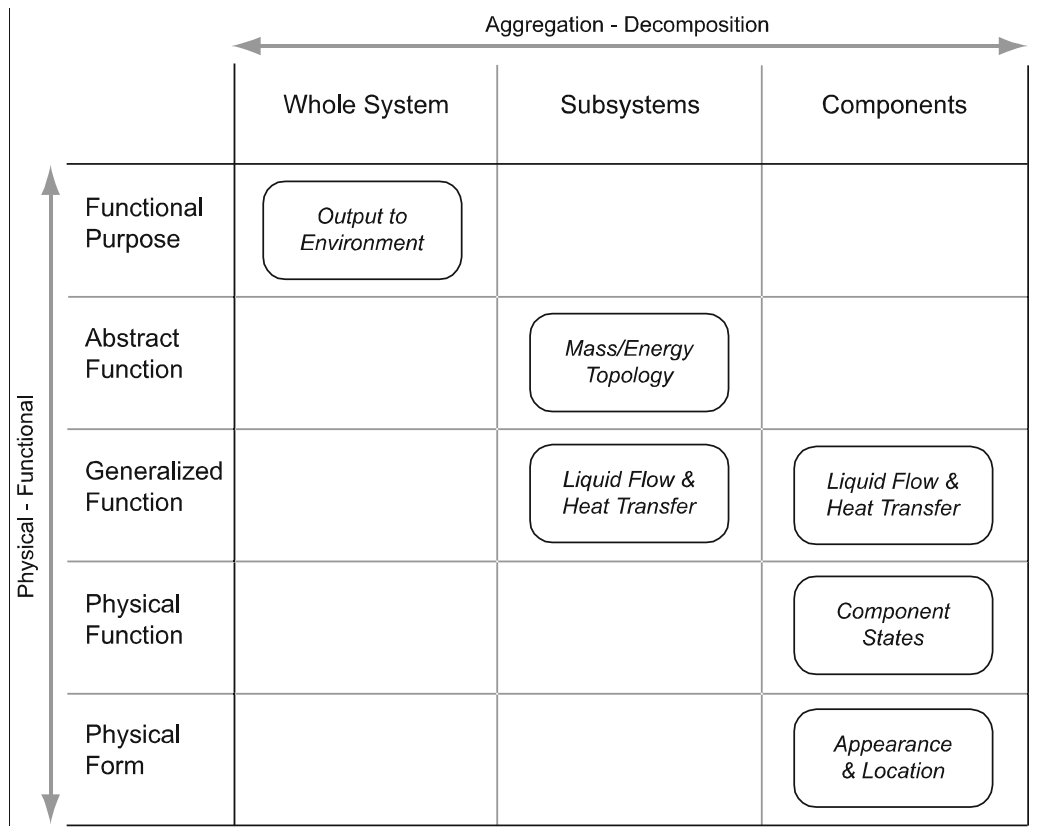

Fig. 3 Abstraction and decomposition (cf. Vicente 1999, p. 318)

operational purposes and contexts. For example, it will be necessary to view the physical situation if there is a need of action on this level. To check whether a railway track is physically usable after a blizzard, one needs to see the physical condition of the iron track. To decide whether a train may enter a station, one needs to check closed and reserved routes and their availability on the generalized functional level.

In addition, the abstraction hierarchy can be extended into a second dimension called the decomposition hierarchy (Rasmussen 1985a; Rasmussen et al. 1994). Decomposition can be understood as the multilevel hierarchy of a system starting at the overall system and leading down stepwise to its subsystems and final components (Fig. 3). It allows us to focus on a special part and its technical properties. For example, if there is a problem with the availability of an engine during flight, the pilot will need to focus on all engines, their power states and the fuel available, but not on the state of other subsystems in the airplane like the aircondition system or the landing gear.

The utility and usability of information based on abstraction and decomposition structures can be defined by a systematic reduction of complex information with respect to a system view (structural decomposition) as well as a process view (functional abstraction). The nodes in this two-dimensional grid must be associated with states, events and tasks to support the human operator in the recognition of situations as well as the planning and execution of activities. In most process control systems we will find examples of the usage of these abstraction and 
decomposition concepts. However, the information provided in a real system is rarely structured systematically according to these dimensions because of information missing, high development effort or other reasons.

\subsection{Decision Ladder for Event-Based Activities}

One of the main situations of operators in highly automated environments is the observation of the dynamic processes and the readiness for handling of events that emerge more or less unexpectedly. The process of perceiving events and reacting with appropriate actions can be described as a multi-staged cognitive processing pipeline which has been called the decision ladder by Rasmussen (1985b). We have already seen one perspective of this decision ladder when we discussed skills, rules and knowledge combined with the information qualities signals, signs and symbols. The decision ladder can be presented in greater detail during the cognitive process of perceiving events, processing information and planning and executing activities to bring the system from an abnormal state to back to normal operation (cf. Fig. 4).

With respect to information ergonomics, the main question is how signals can be enriched by further information and insight about their meaning until a system state can be derived from these perceptions. Having identified a system state the operator is usually able to recognize whether this state is an acceptable safe state or whether it is abnormal and needs to be regulated and changed into some goal state for normal operation. The main information enrichment steps in this perceptual process are:

1. Activation: detection of a need for information processing;

2. Observation: gathering of data and changing these data into perceived information;

3. Identification: derivation of a system state from this perceived information;

4. Interpretation: effects of the system state for operation and safety;

5. Evaluation: acceptability of the system state or safe procedures for its regulation.

The quality of a control system stems partially from its capabilities to present data to fulfill these steps in a timely and correct manner. The operator has to be supported in the perception and memorization process before any reasonable activities to handle the event can take place. Whenever this chain of informational perception will lead to an early recognition of actions that have to take place, the operator might apply shortcuts performing these activities (cf. Fig. 4). While going for these shortcuts the operator will leave out the complete bottom-up analysis and will try to react as fast and direct as possible. Whether these shortcuts will be adequate and lead into a safe goal state depends on the quality of information perceived and on the experience of the operator. Weak information and low competencies will lead to suboptimal or incorrect activities that might even aggravate the situation.

Information systems within transport systems must inform about system states and guide the regulation from abnormal to normal operation. Each stage of the 


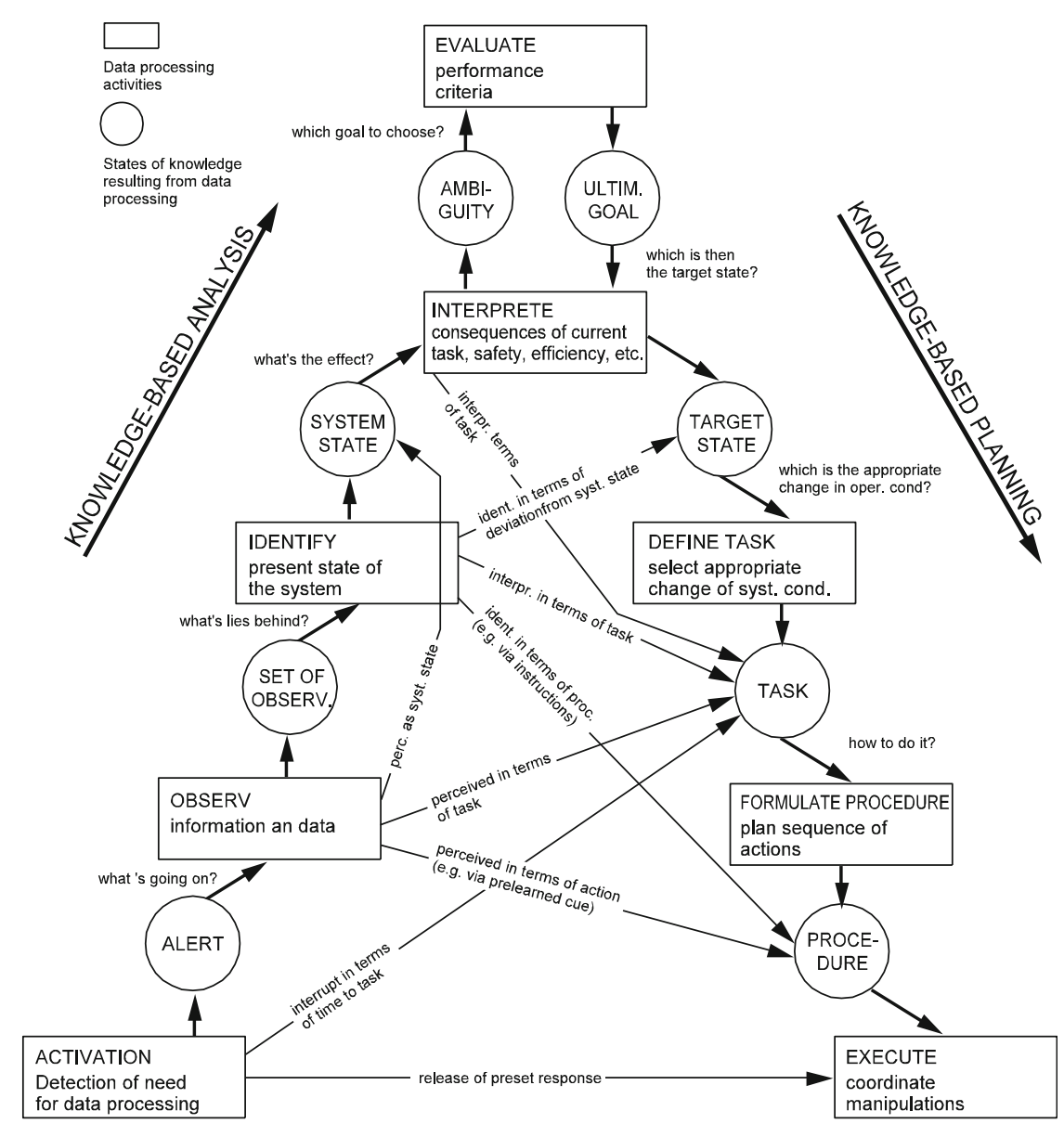

RULE - BASED SHORTCUTS

Fig. 4 Decision ladder for process control (cf. Rasmussen 1985b)

decision ladder requires a different information quality. Given information will be enriched and focused until the perception of system states and regulatory activities emerge.

\subsection{Situational Awareness and Decision Making}

While Rasmussen's decision ladder concentrates on a current and a goal state, there is no explicit consideration of the operator's anticipation of a future state. This 
aspect has been taken into account in the model of situation awareness (SA) by Endsley (1988).

One definition of situational awareness specified by Endsley (1988) and cited in numerous publications is: "The perception of the elements in the environment within a volume of time and space, the comprehension of their meanings, and the projection of the status in the near future" (Endsley 1988, p. 97). In this context Endsley differentiates between three levels of situational awareness:

- The first level comprises the perception of relevant cues from the environment (also media-based information).

- The second situational awareness level (comprehension) includes the recombination of the perceived cues to form a conclusive picture and the interpretation and storage of this picture with respect to their relevance regarding goals (the forming of a correct picture of the situation is based on perception).

- The third level of situational awareness describes the capability of projecting the "conclusive picture" generated in the first two levels to situations, events and dynamics in the future, thus initiating actions which guarantee and ensure high quality of performance and safety.

Figure 5 illustrates the cognitive processes determining situational awareness. Endsley (1995) clearly distinguishes between situational awareness, decisionmaking processes and performing actions. Endsley also differentiates between situational awareness as a result of the acquisition of information and receiving

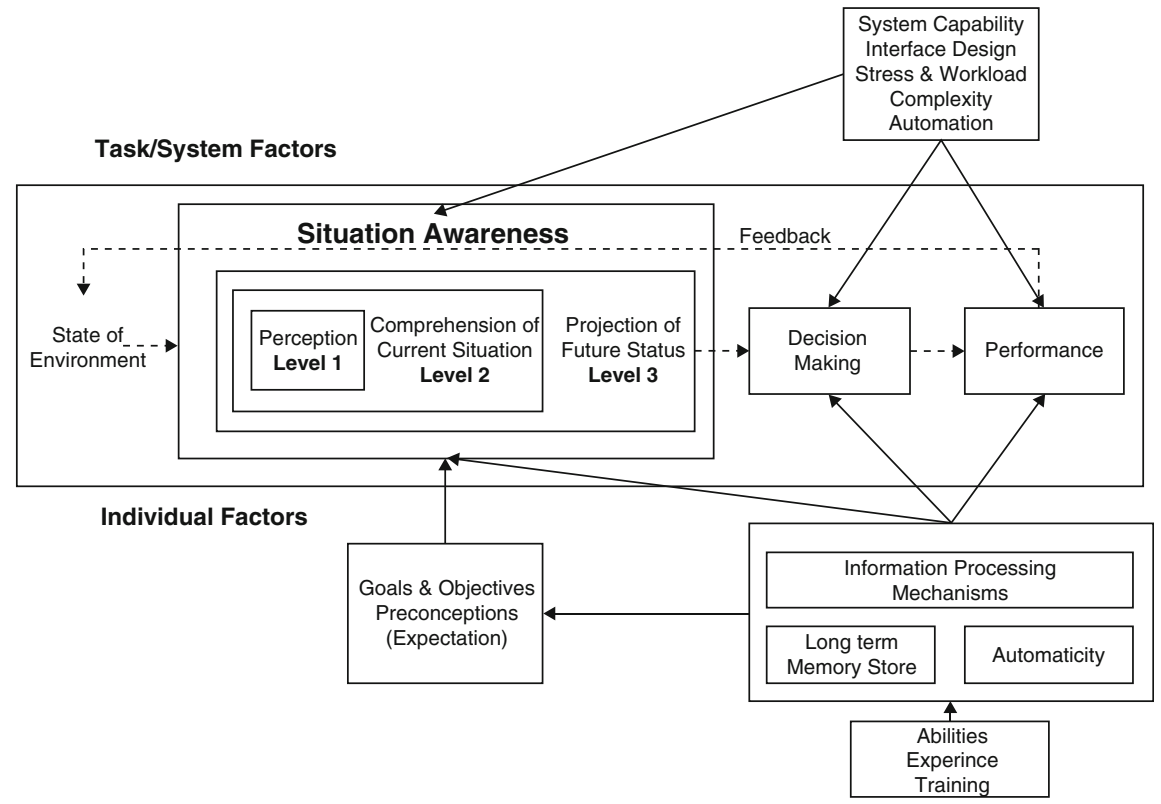

Fig. 5 Model of situation awareness (Endsley 1995) 
information as a process she calls situation assessment. She further explains her situational awareness model, declaring that situational awareness is the main precursor for decision making; however, like decision making and performance of actions, situational awareness is affected by moderating variables, e.g. stress, workload and complexity. Waag and Bell (1997) disagree with this perspective and regard situational awareness in terms of a meta construct in which information processing, decision-making and execution of action are an integral part (cf. Seitz and Häcker 2008).

The limiting variables in the situational awareness process are the limited resources of attention (cf. data-limited and resource-limited processes; Norman and Bobrow 1975) and working memory. The experience of the operator plays a decisive role in dealing with these limitations. Experienced operators actively scan the environment by means of an elaborate cognitive model (in terms of top-down processes, i.e. goal-directed) for action-relevant information. The prioritization between different competitive goals in dependency on the situation seems to be significant. Such highly automated information processing saves the working memory resources on the one hand and contributes to developing more adequate situational awareness on the other.

There are various decision-making processes with regard to the use of information systems within the scope of transportation. The decision:

- Of whether to access an information system (Does the system and environmental state allow attention to be directed to the information system? Is access to the information system required? Is e.g. the "total" situational awareness lost?);

- To be made at what point in time the information system shall be accessed (some phases in a dynamic process can be more or less advantageous for access);

- To be made with regard to how long access to the information system shall last (The operator generally has an idea of how long he can divert his attention from main controls or the monitoring task. Generally he also has an idea of how long the search for information will take. Due to the fact that the system or environmental state changes during the use of the information system a change of goals may result during the search for information.);

- On which information is required (prioritization, if required);

- On the application or rejection of information. (Does the user make a decision on how to act based on the information received or does he make his decision based on other information; Stein 2008?).

A distinction can be made between internal and external situational awareness with regard to the use of information systems within the scope of transportation. External situational awareness means all three situational awareness levels with regard to the system and environment state, e.g. internal situational awareness refers to the use of information systems. Especially in modern aircraft (glass cockpit) the operator must perform less and less control and regulating activities but more and more monitoring tasks. Frequently he only intervenes in terms of regulating and controlling the system if certain critical constellations occur, 
requiring his action. In this regard information systems, e.g. electronic flight bags, are applied. These information systems generally consist of a complex setup of structures similar to hypertext (or hypermedia) as well as several information levels. With regard to use, inner situational awareness means that the pilot knows which part of the information system he is accessing, how to obtain certain information and how to return to the original state.

With regard to the development of the situational awareness construct Seitz and Häcker (2008) currently declare that - similar to the emotional intelligence construct - this has not been fully differentiated and completed. In addition, the authors criticize that there are two deviating concepts of the situational awareness construct and there is no standardization of situational awareness measures. Furthermore, Seitz and Häcker (2008) criticize that many investigations were planned and conducted without reviewing already existing literature. As a consequence, investigational hypotheses are generally not derived based on theory but are "generated" due to operational reasons. This does not contribute to a stringent further development and differentiation of the construct and the theory.

\subsection{Action and Perception for Task-Based Activities}

While we discussed event-based operations, operators will usually perform predefined or even scheduled tasks. In such situations operators refine main operating goals from a high-level task down to the level of physical activities (Norman 1986; Herczeg 1994, 2006a, c, 2009). High-level goals in the field of aviation are, for example, take-off, en-route autopilot flight, change of flight level or landing. Examples of high-level tasks in driving a car are starting the car, parking a car or overtaking another car. Starting with the high-level goal there will be a stepwise refinement of activities through the following levels (cf. Fig. 6 left side branch):

1. Intentional Level: high-level goal;

2. Pragmatical Level: predefined or developed procedures to reach the goal;

3. Semantical Level: state changes to be performed with respect to objects in the problem domain;

4. Syntactical Level: activities to be performed with the control system according to the operating rules;

5. Lexical Level: refinement of the syntactic rules into the multiple levels of super signs (aggregation of signs) and elementary signs (keys, buttons, icons, names, etc.);

6. Sensorimotorical Level: physical actions to execute a step.

After the activities have been performed on the physical level, the control system will receive the commands, process them, react and provide feedback to the 


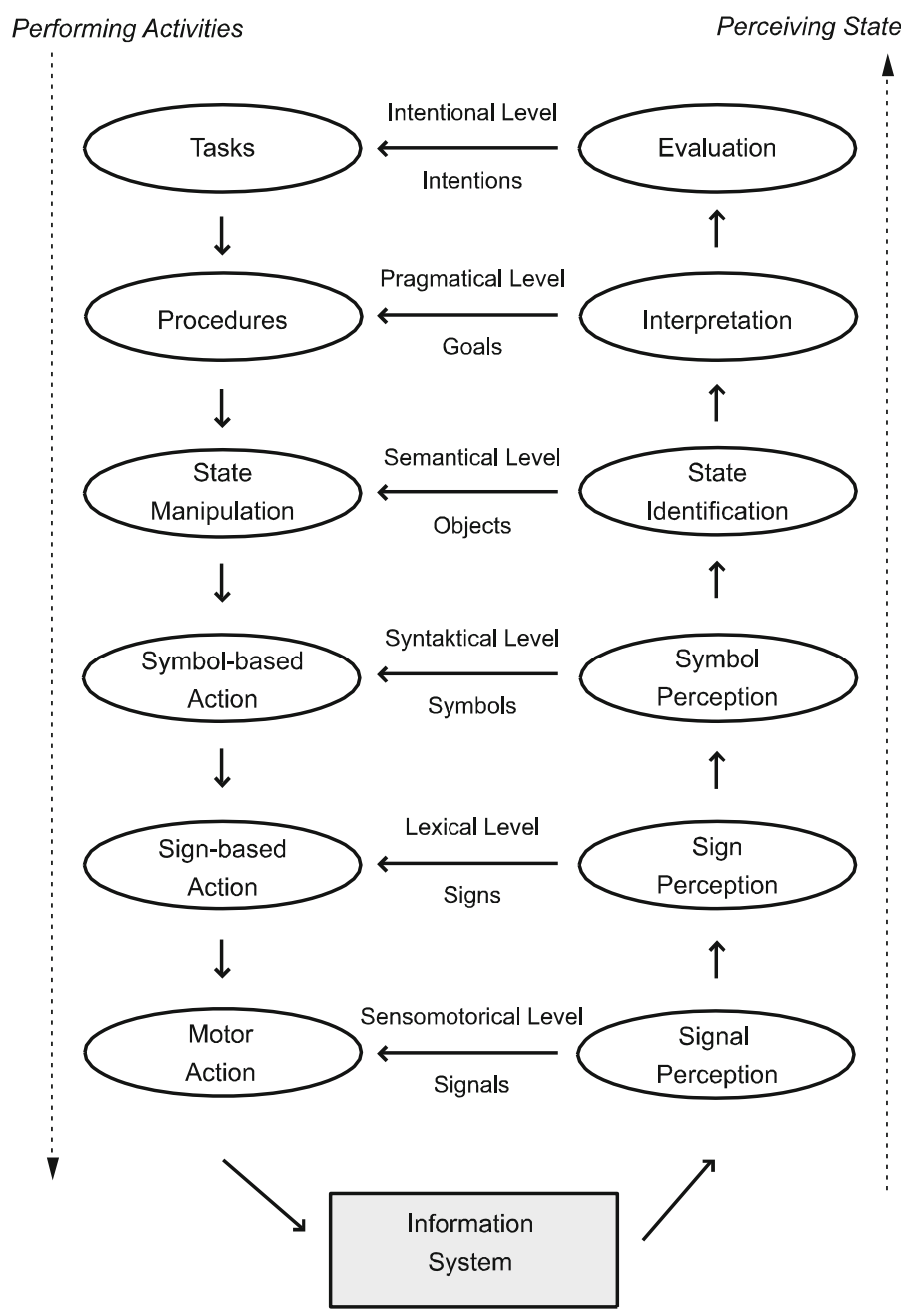

Fig. 6 Levels of interaction when performing a task (cf. Herczeg 1994, 2006a,c, 2009)

operator. The physical process itself might result in directly perceivable feedback in addition to the control system feedback. The operator will then perceive these feedbacks. Just as the activities had to be broken down from a task level down to the sensomotorical level, perception will take place vice versa (cf. Fig. 6 right side branch). This is quite similar to Rasmussen's decision ladder. One difference is a breakdown into the six levels as described for the breakdown of activities. Another difference is the observation that the operators set up expectations for system reactions of a certain kind on each level (anticipation). During the breakdown of activities they develop expectations of how the system should react according to their activities. These expectations will be used in guiding the perception process to 
check whether the activities have been successful. Any derivation from the expected outcomes might be reflected critically and can be a trigger for activity regulations on the level where the differences have been detected. As a result, errors may also occur because the operators are biased and focused on their expectations (Herczeg 2004). Quite similar to the decision ladder, the quality of the information presented to the operators will be vital in order for the regulations to be adequate and successful. An interesting part of this regulation process are the memory structures, the representations of knowledge and the information cues provided by the process control system to support these complex and sometimes fast regulations (real-time systems) on the different levels.

This model of stepwise refinement of high level tasks down to sensomotorical activities and the perception of system and environment feedback up the hierarchy can be transformed into Rasmussen's decision ladder when we start with system reactions (events), go up the perception hierarchy and back down the ladder of stepwise refinement of activities to cope with the situation. Therefore, both models seen from a psychological point of view are just two different perspectives of the same process. Tasks and events are just opposite sides of a process control situation. Tasks are refined into activities resulting in system reactions and events are system reactions to be perceived and translated into tasks. The information structures within these two models are basically the same. As a result, there is a good chance of designing one information system that can be used for task-oriented as well as event-oriented operations, which does not mean that both operational modes are the same. There are special operator needs to understand, plan and execute tasks as well as needs to recognize, interpret, evaluate and handle events. A common model will be part of the holistic model discussed later in this chapter.

\subsection{Human Memory and Its Utilization}

Information needs to be stored and represented in the human memory to be available for further processing and problem solving. Since the first models of human information processing there have been models describing the human memory and its characteristics.

An early groundwork of the understanding of the human memory was provided by George A. Miller's influential paper "The Magical Number Seven, Plus or Minus Two: Some Limits on our Capacity for Processing Information" (Miller 1956). His empirical work refers to a capacity limit of $7 \pm 2$ memory chunks of the human memory during perception of information and problem solving. This was the discovery of an "immediate memory" with certain access and coding properties. It was later called and conventionalized as the human short term memory. Additionally the abstract notion of a chunk as a memory unit leads to the remaining open question about the coding principles of human memory. However, in his 1956 paper Miller notes: "[...] we are not very definite about what constitutes a chunk of information." 


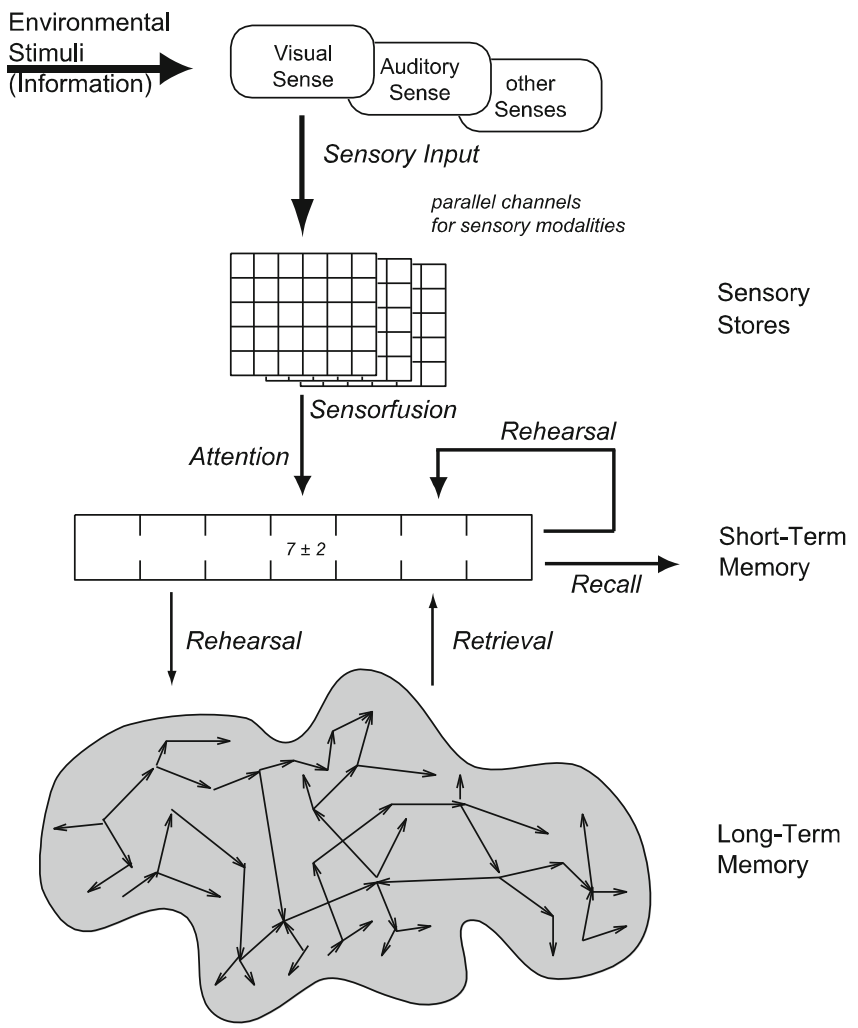

Fig. 7 Stages of human memory (cf. Herczeg 2009)

Miller's work and the later search for the characteristics or even properties of human information perception and information processing lead to models of multistaged memory structures. Many researchers, such as Atkinson and Shiffrin (1968, 1971) as well as Card et al. (1983) developed similar multi-staged memory-models describing different types of memory usually starting with a sensory memory, feeding a short-term memory (STM) often called working memory, and collecting and structuring the memory chunks inside a so-called long-term memory (LTM). The memory stages are connected by memory mechanisms referred to as attention, retrieval, rehearsal and recall (cf. Fig. 7). Every memory stage or type has its own properties for access time, capacity, persistence or coding.

Generally, the value of this and similar models has been the insight that the human memory is not just an array of memory cells, but a highly differentiated active and dynamic structure of different memory types with specific performance characteristics. The differences lead to explanations why human memory succeeds or fails with respect to selectiveness, capacity, speed, accuracy or persistence. When it comes to the question of the memorization process in a scenario from 
information displayed in a cockpit to the recognition and storage of information, the limitations of the operator's memory become apparent.

By now, current neurobiological research indicates that there are many more memory types for different types of information (visual, auditory, tactile, spatial, temporal, etc.) and that there are quite complex memorization and learning processes within and between them (cf. Ware 2000). As an important step in understanding supervision and control activities of human operators we also need to assume a kind of transition memory for medium-term processes between short-term memory (working memory) and long-term memory (persistent knowledge storage). Some of these open questions about memory structures correspond to the difficulties describing simultaneous regulation processes in the activity hierarchy. The timing in this context ranges from a few milliseconds and seconds to hours and days of working on tasks and events.

A more refined memory model might result in more differentiation of the hierarchy of signals, signs and symbols. This refinement takes into account that there are obvious differences in coding of memory chunks as well as in the rehearsal methods as part of the regulation processes, e.g. visuo-spatial vs. phonological (cf. Baddeley 1999; Anderson 2000). While signals, signs and symbols fit quite well into Rasmussen's initial 3-stage model we need to rethink these models and implications for highly dynamic regulation processes as it is the case in the 6-stage model (cf. Fig. 6). As a proposal we try to work with the following 6-stage information and memorization model to discuss task-driven as well as event-driven control activities. This model will not describe all aspects of memorization or information processing, but it addresses typical information stages needed to explain or support task-based and event-based supervisory control activities (Sheridan 1987, 1988):

1. Intentional Level: goals and intentions

2. Pragmatical Level: symbolic phrases (semantic procedures based on logic)

3. Semantical Level: symbols (references and characterizations of meaningful objects)

4. Syntactical Level: lexical phrases (syntactic procedures based on grammars)

5. Lexical Level: signs and supersigns (basic coding of chunks)

6. Sensomotorical Level: signals and noise

In the field of general semiotics (Nöth 2000) and computational semiotics (Andersen 1997; Nake 2001) we can find descriptions and explanations for these types of activity-based memorization. With respect to information ergonomics we have to think about appropriate externalizations (e.g. presentations on displays) for these activity- and regulation-oriented forms of information. Ware (2000, p. 13) discusses PET- and MRI-based findings about the processing chain for visual symbols from perception to memory. Besides the multi-step neural processing he proposes a more abstract 2-stage model (Ware 2000, p. 26) with parallel processing to extract and match low-level properties of a visual scene as the first stage and sequential goal-directed processing as the second stage. 


\subsection{Search Strategies}

One of the most frequent subtasks of operators is searching for information to accomplish a task or to cope with an event. The search strategies applied by the human operator will depend on:

- The structure of the information space;

- The size of the information space;

- The available keys (cues, input) for the search;

- The time available for the search;

- The quality requirements for the outcome of the search;

- The experience of the operator;

- The emotional state of the operator.

Searching for information in large information structures can be performed by applying different strategies (Herczeg 1994, 2006c). Basic search strategies are:

1. Browsing: The operator randomly searches information structures. In meshed information structures links between information nodes can be followed; in linear information structures a partially sequential search will be performed with more or less random jumps to other sequences of information (Fig. 8).

2. Exploration: The operator explores the information space more or less systematically. As a side effect of the search an overview (mental map) of the search space can be established. The map is a kind of meta-information (Fig. 9).

3. Navigation: In structured information spaces an operator may use a mental or physical map (meta-information) to guide the search and find the information needed generally faster than searching without the map (Fig. 10).

4. Index-Based Search: For a faster search an information space may be indexed, i.e. direct links leading from a list of keywords or a table of content to the information are available. The operator first looks up the information needed in the index and follows the link to the information itself from there (Fig. 11).

5. Pattern-Based Search: If the information needed cannot be indexed by precise keywords or a table of content, it might be looked up via diffuse search patterns (regular expressions) that are similar or somehow related semantically to the information. More or less intelligent search engines resolve the search pattern into references to information available in the information space and somehow related to the search pattern (Fig. 12).

6. Query-Based Search: In well defined and structured information spaces (information models) like databases, information search can be conducted using structured logic and algorithmic search specifications. Query languages and query interpreters resolve the query into references to the selected information contained in the information space (Fig. 13).

Information systems in safety-critical domains must often cope with the tradeoff between time required for the search and quality of the search results. It is one of the major challenges of the design of such systems to take this into account, i.e. to 


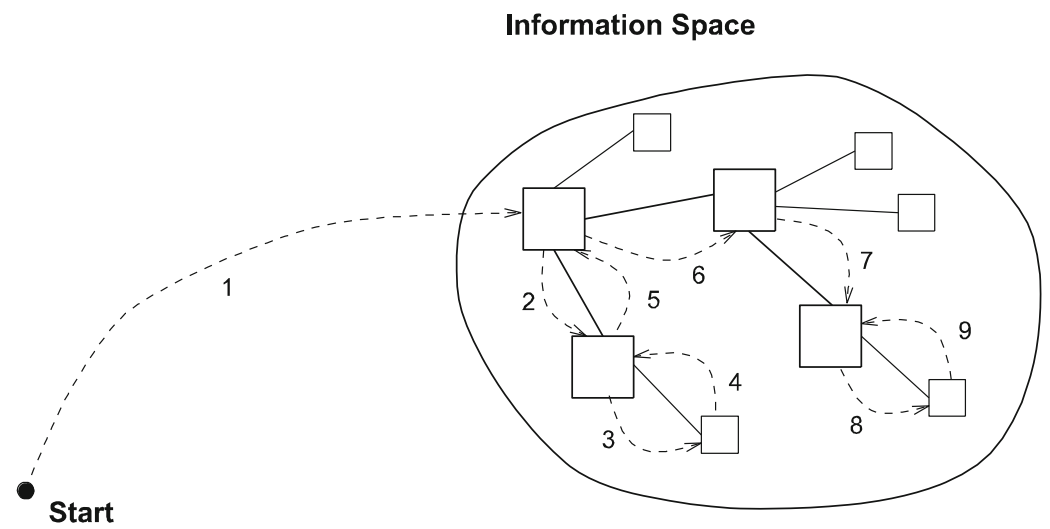

Fig. 8 Browsing

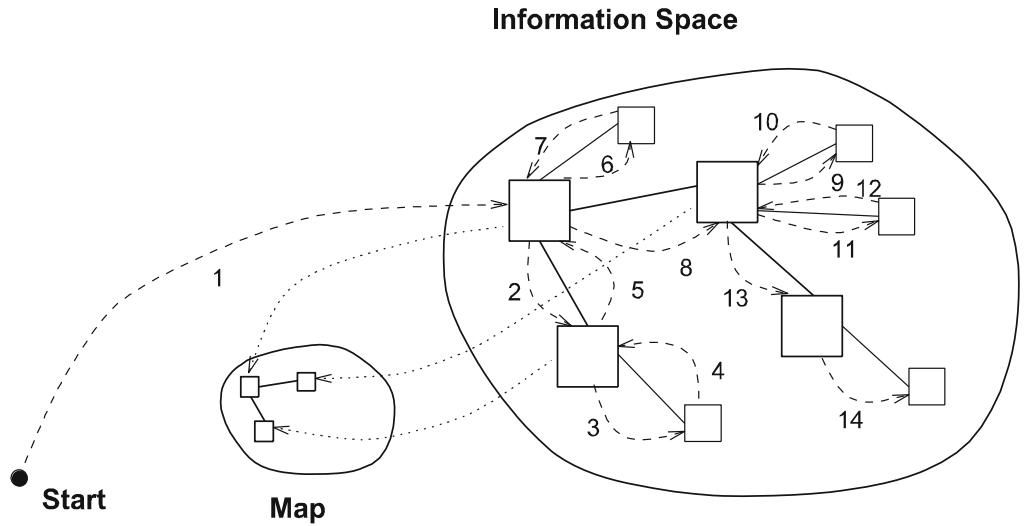

Fig. 9 Exploration

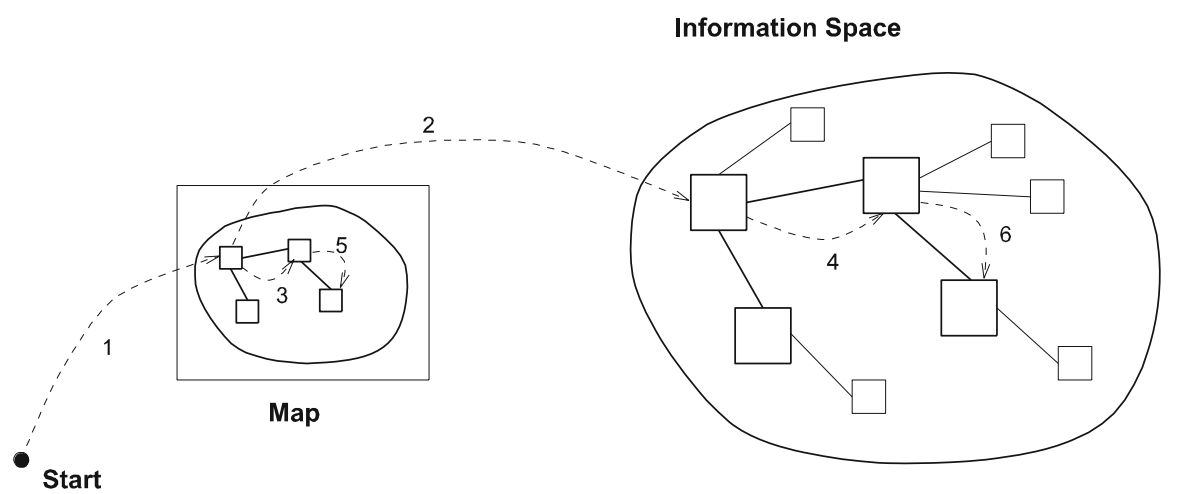

Fig. 10 Navigation 


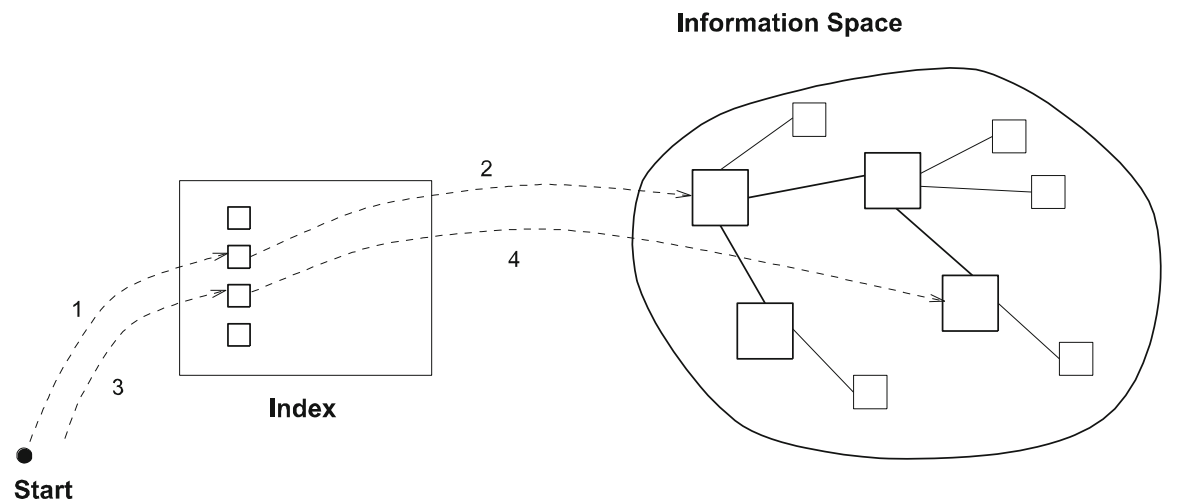

Fig. 11 Index-based search

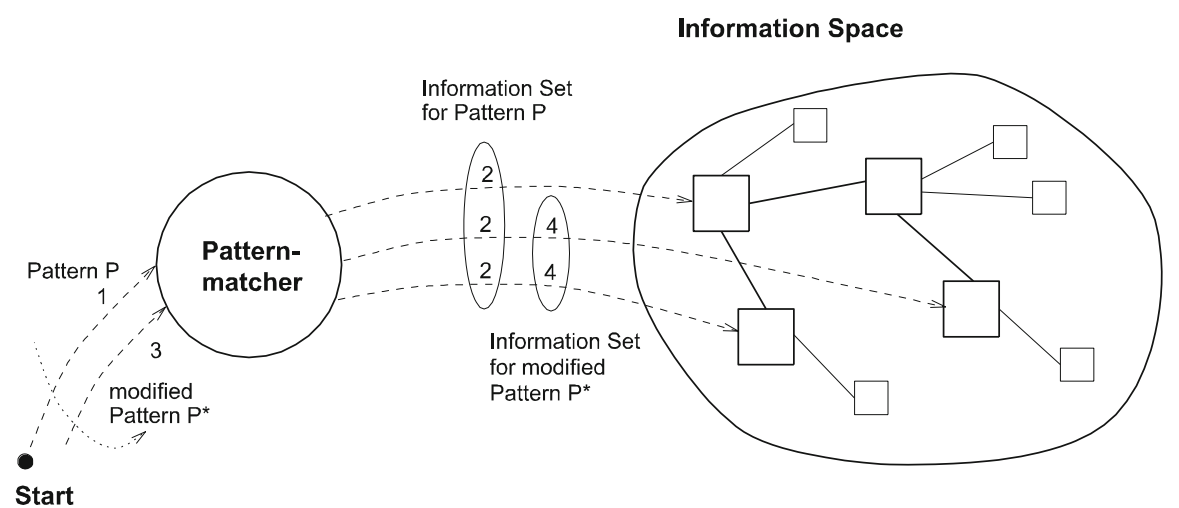

Fig. 12 Pattern-based search

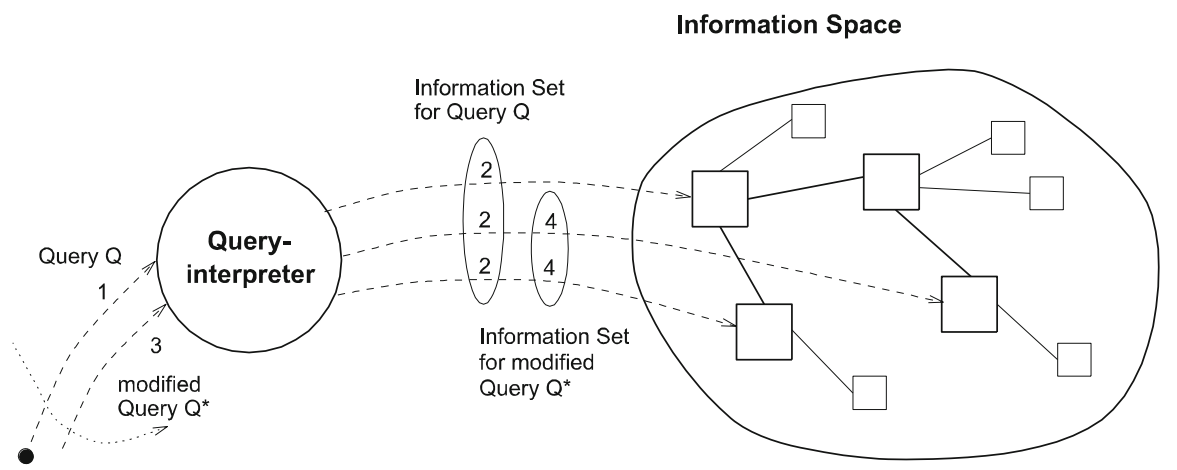

Start

Fig. 13 Query-based search 
provide search support which is time- and quality-sensitive with respect to the current operating context. As a pragmatic approach the provision of sufficiently appropriate results within the available time frame will be the rule. These have been called satisficing solutions (Simon 1981). Complete and best results will be the exception. For the operator it is important not only to be able to specify the search and obtain results, but to receive feedback about the progress of the search process and the quality of the results.

In many cases search will be related to the phenomenon of serendipity. Important information found is not always related to appropriate search strategies and search goals. In complex information systems many interesting and important facts will be found just by accident. Sometimes this disturbs the process of a systematic search and sometimes it results in satisficing and appropriate solutions.

Specifications of search, feedback for the ongoing search processes, and the presentation of the results will vary between the application domains, the experience of the operators and the contexts of operation. Much work has been done in the area of the visualization of results. Lesser work has been done in the area of progress and quality indications for search results and for other than visual information, like acoustic and haptic search feedback.

\section{Limits of Current Cognitive Models}

The cognitive models described can also be criticized with regard to their "mechanistic design" (cf. Dunckel 1986), even though they partly illustrate different aspects of action regulation. Crucial behaviour-determining constructs like emotion, motivation and processes of goal definition are not model-imminent or not differentiated sufficiently. In addition, there are no exact presentations and descriptions of operator's evaluation processes (preliminary evaluations) - becoming manifest in emotions - which in turn represent a driving force for the completion of actions and the initiation of subsequent actions (Stein 2008).

A further point of criticism is the memory of action-relevant knowledge, since Rasmussen (1983, 1986), for instance, did not reflect on a memory model or cognitive processing (cf. Dunckel 1986). It must be assumed, however, that certain action patterns are stored over a prolonged period of time to be retrieved when they are needed.

Furthermore, it should be noted that social processes and interactions or also organizational processes - in which action is usually integrated - are not detailed and referred to in the models described (cf. Cranach and Kalbermatten 1982).

Most of the cognitive activity models described in the previous sections are characterized by a clear separation and discrimination of the subprocesses. The problem with these kinds of models is that we can also observe certain effects that cannot be associated with these models, e.g.: 
- Operators do not proceed systematically in the order of these levels; instead they jump between model levels, omitting certain steps (cf. the shortcuts of Rasmussen's decision ladder);

- Operators developmental models (e.g. Carroll and Olsen 1988) that enable them to mix model levels and show performances that are more holistic than substructured; for example the mixture of syntactic and semantic information processing enables human operators to disambiguate perceived signs to symbols (Herczeg 2006b, c);

- Cognitive and emotional models need to be combined to explain certain human behaviour in control tasks; historically cognitive and emotional models have been discussed and analyzed mainly separately;

- Human memory models have to be redefined through current findings about brain structures and neural processing; for example the idea of a staged memory (e.g. Miller 1956; Atkinson and Shiffrin 1968, 1971; Wickens and Hollands 2000) does not describe memorization or learning processes very well;

- Multiple and parallel activities can only be partially understood by applying the available activity and the resource models (e.g. Wickens and Hollands 2000); we need a more complex combination of these models which describe the multiprocessing abilities of human operators more appropriately.

Humans can perform several activities at the same time. This is sometimes called multitasking. Some of the activities take place consciously, but many of them are performed subconsciously, i.e. we are only partially aware of them. The discussion of activity models (cf. Fig. 6) revealed different levels of activities and regulation processes. Activities on a higher level are refined into more fine-grained activities on the next lower level. Low-level perceptions are analyzed and enriched to some fewer higher perceptions. If the perceived signals, signs or symbols do not correspond to those which have been anticipated, regulation may be applied. As a result of this activity refinement and perceptual aggregation we will have many parallel regulation processes proceeding on different levels, some of them consciously (mainly the upper levels) and some of them subconsciously (mainly the lower levels). Additionally, several dependent or independent tasks can be started and performed in parallel.

How and to what extent will an operator be able to follow and control tasks which are performed simultaneously? The models available for describing the resources and capacities to perform these processes (e.g. Wickens and Hollands 2000; Endsley 2000; Herczeg 2009) as well as the resulting load, strain and stress do not correspond in every respect to the complexity, the memory effects and time structure of such simultaneous activities. The current models can mainly be used to discuss coarse-grained effects of multitasking. This affects the design of information systems for real-time contexts like transport. How can we optimize information displays when we do not have a fine-grained understanding of multiple activities in real-time situations? The approach that has been used is to give the operators any information they might need, observing the overall performance and the standard errors occurring. This results for example in cockpits which are filled with controls 
and displays, many of them multi-functional, leaving the usage and adaptation to the operators and their capabilities. More context- and task-sensitive environments could provide better selective support of operations by presenting the main information needed, by checking time conditions to be met and by controlling the performance of the operators. The concept of Intention-based Supervisory Control (Herczeg 2002) proposes smarter process control environments, taking into account which activity threads are ongoing between a human operator and a semi-automatic control environment.

Models and automation concepts for multiple parallel activities should be discussed and developed with respect to multiple operators and multi-layer automation (Billings 1997) to optimize the dynamic real-time allocation of tasks between human and machine operation.

The following shall outline an extended model for describing action regulation during access to an information system, observing and acknowledging the described strengths and weaknesses of the already presented models. The design of this model is based on the presented models, however, in particular motivational and emotional processes, the formation of expectation as well as expectation-valuecomparisons during access to an information system are modelled. To this end, all relevant constructs, e.g. motivation and emotion, cognitive resources and workload, effort regulation, fatigue and stress are initially described and subsequently put into an overall context for the field of information systems in transportation.

\subsection{Motivation and Emotion}

The intention of motivation psychology is to "(...) explain the direction, persistence, and intensity of goal-directed behaviour. (...) the two main, universal characteristics of motivated behaviour are control striving and the organization of action" (Heckhausen and Heckhausen 2008, p. 3; Schneider and Schmalt 2000). In this context Heckhausen and Heckhausen (2008) differentiate between goal engagement and disengagement. The former involves focusing (attention, perception) on triggering stimuli, the fading out of goal- and action-irrelevant stimuli and the "provision" of partial actions. Therefore the expectation of the effectiveness of the planned behaviour is optimistic. In contrast, goal disengagement can result when the expected effectiveness exceeds the costs of behaviour. This includes a devaluation of the endeavored goal and the enhancement of the value of alternative goals. The processes of goal engagement and disengagement play a major role in the use of information systems. This is due to the fact that information access happens in a dynamic environment and thus priorities must be assigned to several competing information goals. Furthermore, depending on changing environmental, process and system states a decision must be made during the search process on whether to continue the information search or discontinue the search in favour of other information goals or also other activities. In order to be able to model the motivational aspects of the access to an information system a general motivation 


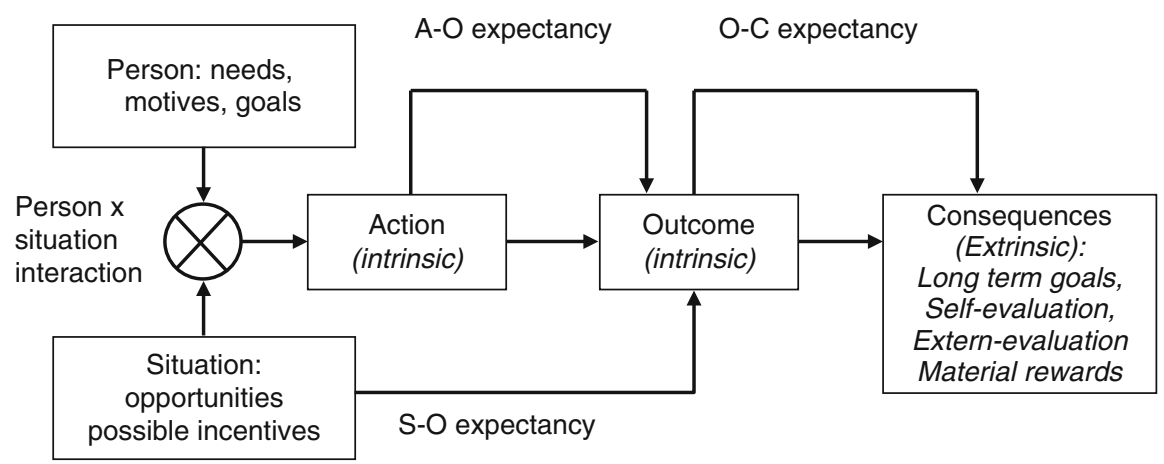

Fig. 14 A general model to describe the determinants of motivated action (Heckhausen and Heckhausen 2008)

model by Heckhausen and Heckhausen (2008) can be used as a basis to describe the determinants and the process of goal-directed behaviour.

As Fig. 14 shows, the motivation of an individual is determined by the interaction between personal and situational factors as well as anticipated outcomes and longer term consequences. With regard to personal factor described in the model, Heckhausen and Heckhausen (2008, p. 3) differentiate between:

- Universal behavioural tendencies and needs (e.g. hunger, thirst),

- motive dispositions (implicit motives) that distinguish between individuals, and

- the goals (explicit motives) that individuals adopt and pursue.

For the use of information systems explicit motives (self image, values, and goals) are relevant because they can be described as the superior layer for achieving information goals. However, motives like curiosity (particularly with regard to complex systems which the operator cannot cover by cognitive means), achievement motivation (implicit motives), and safety are also of great importance. In flight simulators, for instance, we can observe pilots exploratively investigating information systems. Since this is also the case for system-experienced pilots we can draw the conclusion that the complexity of information systems cannot entirely be covered cognitively, leading to a reduction of insecurity by means of explorative investigation (curiosity).

Apart from the personal factors already described which contribute to motivational tendency certain situations implicate cues perceived by individuals as possible incentives or opportunities. These stimuli which may have positive or negative connotations are associated with action, the outcome of action and also the consequences of action. With regard to situations Heckhausen and Heckhausen (2008) differentiate between situation-outcome-expectancy, action-outcomeexpectancy and outcome-consequences-expectancy. The first-mentioned expectancy means that results will come to pass even without performing own actions - i.e. situation-dependently - and thus initiation and performance of action is improbable. In contrast, goal-oriented action is performed in case situation-outcome-expectations 


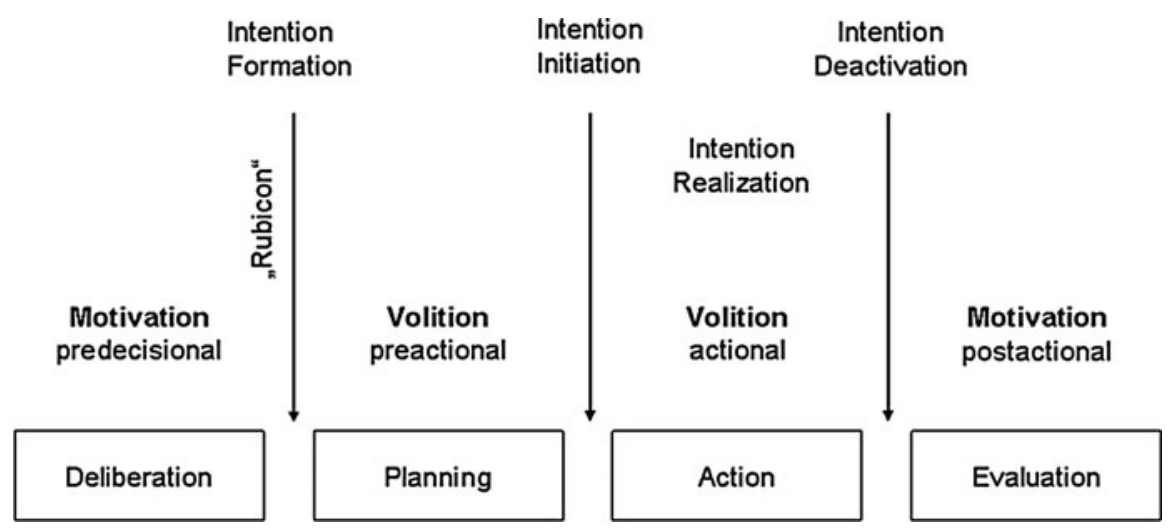

Fig. 15 The Rubicon model of action phases by Heckhausen and Gollwitzer (1987)

are low, while at the same time action-outcome-expectations and outcomeconsequences-expectations are high.

If congruency is obtained between the characteristics of a motive and the possible incentives a motivational tendency will result. This tendency, however, is not sufficient for an individual to "feel" closely connected to action goals or for goal-oriented action. Heckhausen and Heckhausen (2008) explain that intention should emerge from a motivational tendency. They illustrate the individual phases from the formation of intention to the action and the evaluation of the action in their Rubicon model. Figure 15 shows that they differentiate between motivation (predecisional and postactional) and volition (preactional and actional).

The deliberation phase (predecisional) is characterized by wishes and contemplation of pros and cons concerning potential goals (Heckhausen 1989). In this context, especially the assessment of the feasibility of one's goals in terms of practicability with regard to the context or environment of action and one's own capabilities play a decisive role. The anticipated implementation of the goals is also evaluated. "The expected value depends on how disagreeable or agreeable the potential short- or long-term consequences and their probability of occurrence are estimated to be" (Gollwitzer 1996, p. 534). Since the process of deliberation is not continued indefinitely Heckhausen (1989) assumes a "facit tendency (concluding)". This tendency implies that the more comprehensively a person has deliberated the information available for a decision and the longer the process of deliberation takes the closer he or she perceives the act of making a decision. When a decision about an action alternative has been made, leading to an intention, the person feels committed to achieving the goal (Gollwitzer 1996; Heckhausen 1989). Heckhausen and Gollwitzer (1987) call this process "crossing the Rubicon".

In the planning phase (preactional, volition) the focus is on the schedule of actions to achieve one's goals. According to Gollwitzer (1996, p. 536) "primarily the 'when' and 'where' of the initiation of action as well as the 'how' and 'how long' of the progress of action is dealt with in this phase with the objective of committing oneself to one of the many possibilities, initiating, performing and 
completing goal-implementing action". Whether an intention is implemented into action and realized depends on the volition strength of the intention in relation to the volition strength of other, competing intentions and on the evaluation of the action context (favorable, unfavorable) with regard to initiation. Heckhausen (1989) points out that usually many intentions which have not been implemented are on hold during the preactional volition phase in a sort of waiting loop, "competing with each other for access to the action phase". In this phase a certain action can, for instance, be postponed due to an unfavorable context and more favorable action alternatives may be performed for the time being.

According to Gollwitzer (1996, p. 537) action initiation is the "transition to the actional phase. Goal-directed action is characteristic of this phase". Action control is implemented by means of mental models and goal presentations (Heckhausen 1989; cf. Miller et al. 1960; Volpert 1974; Hacker 1978, 1986). Goal achievement is evaluated in the postactional motivation phase. One of the questions arising in this phase is "whether the actual value of the achieved goal corresponds to the expected value" (Gollwitzer 1996, p. 538). These evaluations generally result in a more adequate assessment of the value of a goal intention in future decision-making processes in the predecisional phase.

When observing the process of accessing an information system as well as the reception and cognitive processing of information, i.e. the implementation of information into a process control task, the following motivational phases illustrated in Fig. 16 can be differentiated:

- Motivation for information system access,

- Maintaining motivation within the information system,

- Appraisal of informational content (with regard to the process control task),

- Motivation for implementation,

- Outcomes of implementation, and

- Appraisal of the total "information" process (Stein 2008; Stein et al. 2002).

With reference to the general motivation model by Heckhausen and Heckhausen (2008) described above, personal and situation-related factors play a behaviourinitiating and determining role with regard to accessing information systems (motivation for information system access). This is the case, for example in aviation, when a pilot accesses an information system (e.g. electronic flight bag). In this context the determinants for a motivational tendency are goals (e.g. safe control of an aircraft, accuracy) and goal prioritization (e.g. safety is more important than personal needs) as well as the expectations of the operator (e.g. consulting an information system might be helpful in bad weather conditions) on the one hand and situational factors, e.g. a certain system state (e.g. engine failure) which is indicated on a display on the other. After a motivational tendency has become a goal-directed intention and goal-directed action (information system access), motivation must be maintained in the "information system space" and during the search for information.

After the information has been found and cognitively processed it is integrated into process control after its relevance has been considered. Subsequently, the total 
Overall appraisal

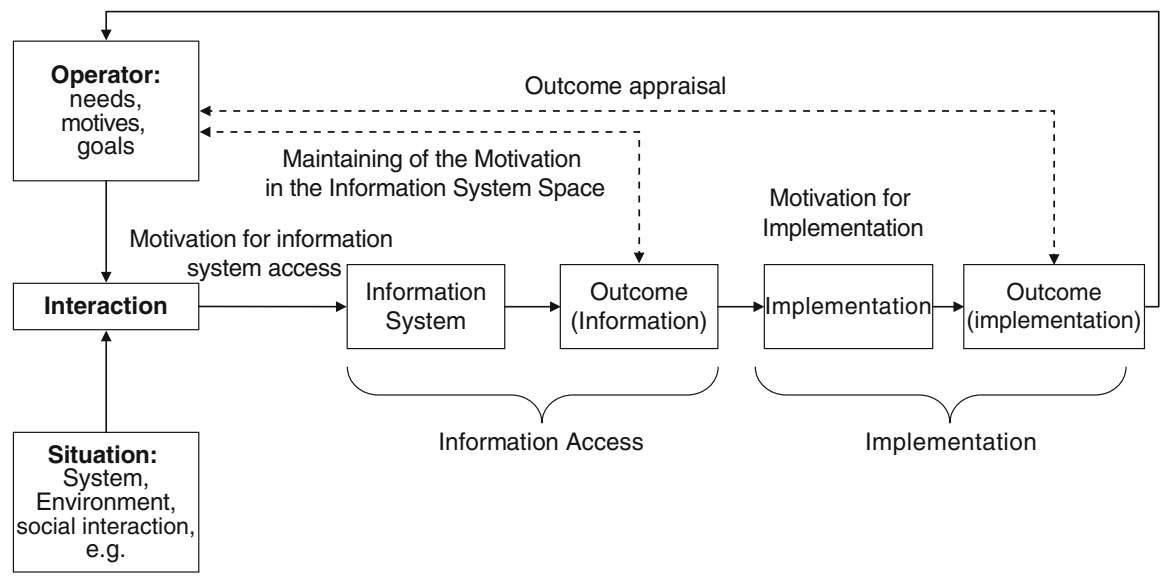

Fig. 16 Motivational phases when accessing an information system and implementing information (Stein 2002, 2008; Stein and Müller 2005)

process starting with information access up to the implementation is evaluated by the operator. The built-up expectations (anticipated information) are compared to the result and evaluated.

Expectations with regard to scope, quality of information as well as handling of the information system play a major role for the emotional processes which represent the evaluation results of the use of the information system as well as the received information (cf. Stein 2002; cf. Sanders 1983). In this case expectations are built up from the information stored in long-term memory which are compared to the "monitor outputs" (information system) in a continuous process, leading to new evaluations (emotions). In turn, these are stored in long-term memory, affecting perception as well as cognition and action selection/implementation.

Emotion is a construct which is closely linked to motivation. In this respect Scheffer and Heckhausen (2008, p. 58-59) state: "emotions can be described as a rudimentary motive system that serves the internal and external communication of motivational sequences. (...) Emotions are thus prerational forms of values and expectancies that influence the motivational process."

Immelmann et al. (1988) define emotion as "physical, intellectual and emotional reactions of an individual to environmental occurrences which are significant to his own needs. This emotional evaluation of a situation often leads to a clear sense of pleasure or aversion, physiological arousal changes and specific action tendencies" (Immelmann et al. 1988, p. 878; cf. Schneider and Schmalt 2000).

Schneider and Dittrich (1990, p. 41) specify three characteristics of emotion:

- "Specific ways of experience" (only perceived by the individual),

- "Motoric behaviour" (e.g. expressional behaviour), and

- "Peripheral physical changes" (e.g. change in blood pressure, transpiration, etc.). 
According to Grandjean et al. (2008) three general approaches to the modeling of emotional mechanisms can be distinguished in affective science:

- Basic emotion models (basic emotions are elicited by certain stimuli, resulting in prototype facial expression, physiological changes as well as certain action tendencies; the various scientific approaches differ in the quantity of assumed basic emotions (e.g. fear, joy, sadness)),

- Dimensional feeling models (feelings are described in the dimensions of arousal, valence and potency, etc.), and

- Componential appraisal models "emotions as a dynamic episode in the life of an organism that involves a process of continuous change in all of its subsystems [e.g., cognition, motivation, physiological reaction, motor expression, and feeling - the components of emotion] to adapt flexibly to events of high relevance and potentially important consequences" (Grandjean et al. 2008, p. 485).

- Neurobiological models (emotions are a product of stimuli categorization either via limbic system ("quick and dirty") or via reappraisal in the prefrontal cortex, see Pinel, 1993).

Scherer (1990, p. 3) postulates that "emotions represent processes, each of which involve various reaction components or modalities". In his Component Process Model Scherer (1984) establishes four phases of sequential assessment:

- Relevance (information is assessed for novelty and entropy),

- Implications (consequences and the impact of the information concerning longterm goals and well-being),

- Coping (strategies to cope with the consequences of the information),

- Normative significance (impact on self-concept and social norms).

Within the scope of information system access and implementation those emotions in particular are significant which the recipient feels and perceives during:

- Information access (e.g. curiosity or the hope of finding the information required quickly and within a reasonable period of time),

- Information search (e.g. annoyance if the path leading to the information is impaired by non-adequate navigational aids or joy after finding the required information),

- Cognitive information processing (e.g. frustration if information is not understood or if high cognitive effort is required to understand the information), and

- at the end of the information retrieval (in terms of an evaluation of the sub- or total process on the basis of which future decisions on information access will be made).

Emotions play a major role for information access, particularly with regard to the operation of complex systems (aircraft, ship, etc.). Thus, certain emotions, for example fear in combat missions with fighter aircraft, can adversely affect cognitive abilities. Consider a fearful pilot who handles a checklist superficially, thus makes a wrong aeronautical decision and misses an enemy on his radar. By this means he might lose a combat mission. 


\subsection{Cognitive Resources}

Common single and multiple resource theories (Wickens 1980, 1984; Norman and Bobrow 1975; Kahneman 1973) are based on a metaphor describing "pools of energy", or resources provided and exhausted during task performance (Szalma and Hancock 2002, p. 1). With regard to the analogy used, referring to the field of economics or thermodynamics/hydraulics, Szalma and Hancock (2002) state that it is not unproblematic to choose a nonbiologic metaphor for a biological system since it can generally illustrate the complexity of living, complex and dynamic systems only to a limited extent.

Early, so-called single resource theories (Kahneman 1973; Treisman 1969 etc.) postulate a singular pool with limited resources/capacities by means of which a multitude of different tasks can be performed. The quality of performance depends on the task demands and the degree of availability of the resources. However, Kahneman (1973) already assumes that cognitive resources can be characterized as dynamic and they are thus subject to certain variability. In this context Gaillard (1993) adds that besides interindividual differences regarding processing capability between operators there are also intraindividual differences depending, for instance, on sleep loss, anxiety or also psychosomatic complaints (cf. Fairclough et al. 2006).

Norman and Bobrow (1975) broadened the single resource theory by Kahneman (1973) to include aspects of resource-limited and data-limited processes. With regard to resource-limited processes a higher degree of effort (also greater exhaustion of resources) leads to improved performance, while in case of data-limited processes performance is dependent on the quality of data (information) with respect to data-limited processes and a higher degree of effort does not contribute to improved performance. Irrespective of the cited differentiation by Kahneman (1973) the most important disadvantage of the single resource theories is that these cannot explain how highly trained operators can manage time sharing of multiple different tasks.

This is where multiple resource theories apply (Navon and Gopher 1979) with humans being considered with multiple information processors. Each channel has its own capacities and resources which can be distributed to different tasks and do not interfere with each other. The Multiple Resource Model by Wickens (1980, 1984) follows this tradition and also represents an explanatory approach regarding the possibility of parallel processing of tasks. Wickens differentiates between four dimensions of independent resources:

- Stages of processing (perceptual, central and response),

- Codes of processing (verbal, spatial), and

- Modalities of the input (visual and auditory) and output (speech and manual).

- Responses (manual, spatial, vocal, verbal)

According to this Multiple Resource Model the cognitive workload increases when the same resources need to be utilized for two tasks to be performed in 
parallel (primary and secondary task). Task demand, resource overlap and allocation policy are workload determinants within the scope of the Multiple Resource Model (Wickens and Holland 2000).

\subsection{Workload}

With regard to the correlation between the workload concept and the Multiple Resource Model, Wickens (2008) explains that both constructs overlap in terms of their contents, although they are separate concepts. With respect to differentiation he further explains that the workload concept is closest related to task demand. However, it is less linked to resource overlap and allocation policy.

This can also be illustrated by a workload definition by Hart and Staveland (1988) in which the authors focus on the correlation between task demands and the required or available cognitive resources the relation of which then determines the extent of workload. "The perceived relationship between the amount of mental processing capability or resources and the amount required by the task".

Hart and Wickens (1990, p. 258) define workload as a "general term used to describe the cost of accomplishing task requirements for the human elements of man-machine-interface". In this regard the costs can be discomfort, fatigue, monotony and also other physiological reactions.

With regard to task demand Wickens and Holland (2000) differentiated between "two regions of the task". In the first region task demand is lower than the resources of the operator. Thus, the operator has residual capacity even in critical or unexpected situations to maintain action regulation. In the second region the demands exceed resources (high workload), resulting in a performance breakdown (Wickens and Hollands 2000).

The significance of the workload concept in the context of user interface design and information systems can be illustrated by the following items by Gaillard (1993):

- When the operator works at the limit of his cognitive resources the occurrence of errors will be more likely;

- Underload can also make the occurrence of errors more likely;

- When the operator works at the limit of his cognitive resources for a longer period of time, stress reactions may result.

There are subjective (workload rating scales) and objective methods (secondary task method, physiological measurement techniques (cf. NATO Guidelines on Human Engineering Testing and Evaluation 2001) which can be conducted to measure workload. When the reasons for high workload have been identified in a workload assessment, the interface design or the task can be modified. 


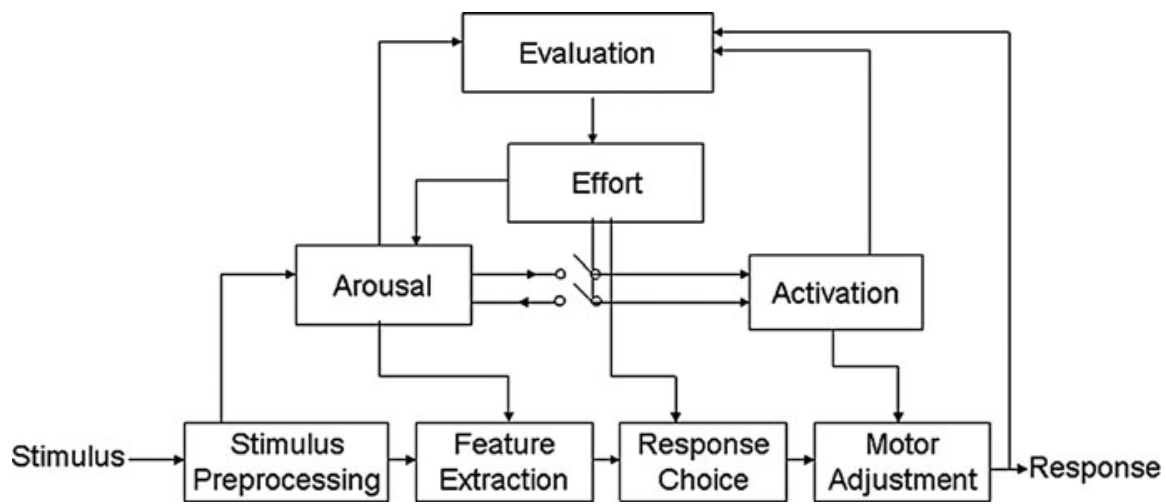

Fig. 17 Model of energetic mechanism (Sanders 1983)

\subsection{Effort Regulation}

In some situations greater effort is required for achieving goals. It is thus possible when using information systems that an information goal cannot be achieved with the effort anticipated by the operator. In this case the operator must decide, depending on the current status of the transportation system and also further environmental factors, whether the effort should be enhanced, the goal should be adapted lower or the information task should be discontinued. Such a decision is generally justified by multiple causes. However, as already mentioned above, an increase of effort can only contribute to an improvement of achievement in resource-limited processes.

Sanders (1983) describes in his model of energetic mechanism the relations between human information processing stages and an energetical system (Johnson and Proctor 2003). In his model he suggests that there are three energetic mechanisms (arousal, effort and activation) allocated to feature extraction, response choice and motor adjustment (cf. Fig. 17). In this context arousal triggers feature extraction, effort triggers response choice and activation triggers motor adjustment. If there are differences between the intended and the obtained response, an evaluation mechanism stimulates the effort level which in turn increases arousal and activation, thus intensifying information processing. If the intended and the obtained result correspond in the evaluation there will be no increase of effort.

When using information systems goals can be achieved also, for instance in case of usage problems, if the operator does not find certain information directly, by means of an increase of effort. If the user is, for example, overwhelmed by the diversity of information or also navigation options (cognitive overload), an increase of effort generally does not result in the desired effects. 


\subsection{Stress and Fatigue}

Stress and fatigue are two constructs which are rarely integral parts of the common action regulation theory. At the same time, the influence of these constructs on the quality of performance and safety, particularly in critical or unpredictable situations, is very significant (cf. Hancock and Szalma 2008; Stein 2008). Particularly in aviation information systems are accessed in critical situations, stress and fatigue having an adverse impact on attention and also on cognitive information processing.

Gaillard (1993, p. 991) defines stress “(...) as a state in which the equilibrium between cognitive and energetical processes is disturbed by ineffective energy mobilization and negative emotions. Stress typically is characterized by ineffective behaviour, overreactivity and the incapacity to recover from work".

Hancock and Szalma (2008) further explain that all stress theories are based on the assumption of an evaluation mechanism which is used to evaluate events with regard to their psychological and physiological relevance (well-being) for the organism. In addition, it is assumed that individuals control internal energetic processes to compensate equilibrium imbalances, e.g. caused by task demands.

The best-known and most elaborated stress theory is published by Lazarus (1974, cf. Lazarus and Folkman 1984). He assumes that there are three levels of event evaluation:

1. Primary appraisal (evaluation of whether an event has positive, non-relevant or jeopardizing effects on the organism. The evaluation of "jeopardizing" is differentiated still further as "challenge", "threat", "harm"/“loss").

2. Secondary appraisal (check if there are sufficient internal resources to fulfill requirements. If internal resources are not sufficient, stress reactions will occur. In this context coping strategies will be developed to be able to handle the situation).

3. Reappraisal (the total event is re-evaluated due to the previous appraisal steps).

With regard to the use of information systems stress occurs if information required for main controls in an emergency situation, for instance, is not available or not available as rapidly as required or if the information does not offer adequate support to solve the problem or an adequate solution approach. Generally, stress is associated with negative emotions (e.g. anxiety, anger, irritation).

Furthermore, stress reactions are accompanied by the following states:

- The operator has problems concentrating on the task,

- More energy is mobilized than is required for the task,

- The energetic state is not adequate with regard to goal achievement, and

- The activation level of the operator remains high, even after the task has been accomplished; the operator has problems returning back to a normal activation level (Gaillard 1993). 
Fatigue occurs in particular in vigilance situations in which the operator for instance fulfills monitoring tasks and in which "signals", which must be observed, are rare events (e.g. during certain flight phases during which the pilot must fulfill only monitoring tasks). In general, the workload during such situations is very low (c.f. Hockey 1986) and is accompanied by a feeling of monotony and fatigue. If information is then urgently required, for instance from the electronic flight bag, the activation level and also its resources are low, so that the organism is not able to react quickly to the requirements.

With regard to the construct of fatigue, Boff and Lincoln (1988) declare that according to the definitions fatigue is frequently associated with a tired feeling, however, an operational definition is difficult. Fatigue is frequently defined as the number of hours of work or hours on duty, although it depends on numerous internal and external factors of each person when fatigue sets in and when it does not. Apart from vigilance situations fatigue can also result from a prolonged high extent of information overload (Hockey 1986).

\section{Regulation of Activities in an Information Task Environment}

Prior to the access to an information system the operator has to identify the requirement and necessity of accessing additional information from an information system based on current system states (e.g. aircraft), environmental or also person internal cues. If, for instance, a flight has to be redirected at the destination airport on short notice due to adverse weather conditions (environmental cues) the pilot will initially recognize the need to find information on the alternative airfield using the electronic flight bag, if he is not familiar with this particular airport. The same is true for the failure of a subsystem, e.g. the hydraulic pressure system (system cues); also, if one of the pilots falls ill or experiences fatigue during a flight and is thus no longer able to fulfil his task fully or not at all the procedure for such a case which is stored in the electronic flight bag will be accessed (person internal cues). The question of whether these cues are perceived and to what degree of accuracy they are perceived generally depends on the competence and experience and also on the self-perception and subjective values of the operators with regard to process control and the information system. These perception processes, i.e. perceiving relevant cues and recognizing and deriving an information task on that basis, constitute the first level of situational awareness. In terms of psychology of motivation these cues serve as opportunities and possible incentives, resulting in motivated behaviour (access to an information system) in the interaction with needs, motives and goals, depending on how pronounced these are; this is described in Chapter "Motivation and Emotion" (cf. Fig. 18).

According to Rasmussen (1983) information tasks without cognitive parts can be processed also on a skill-based level following a cue (skill-based level). In the 


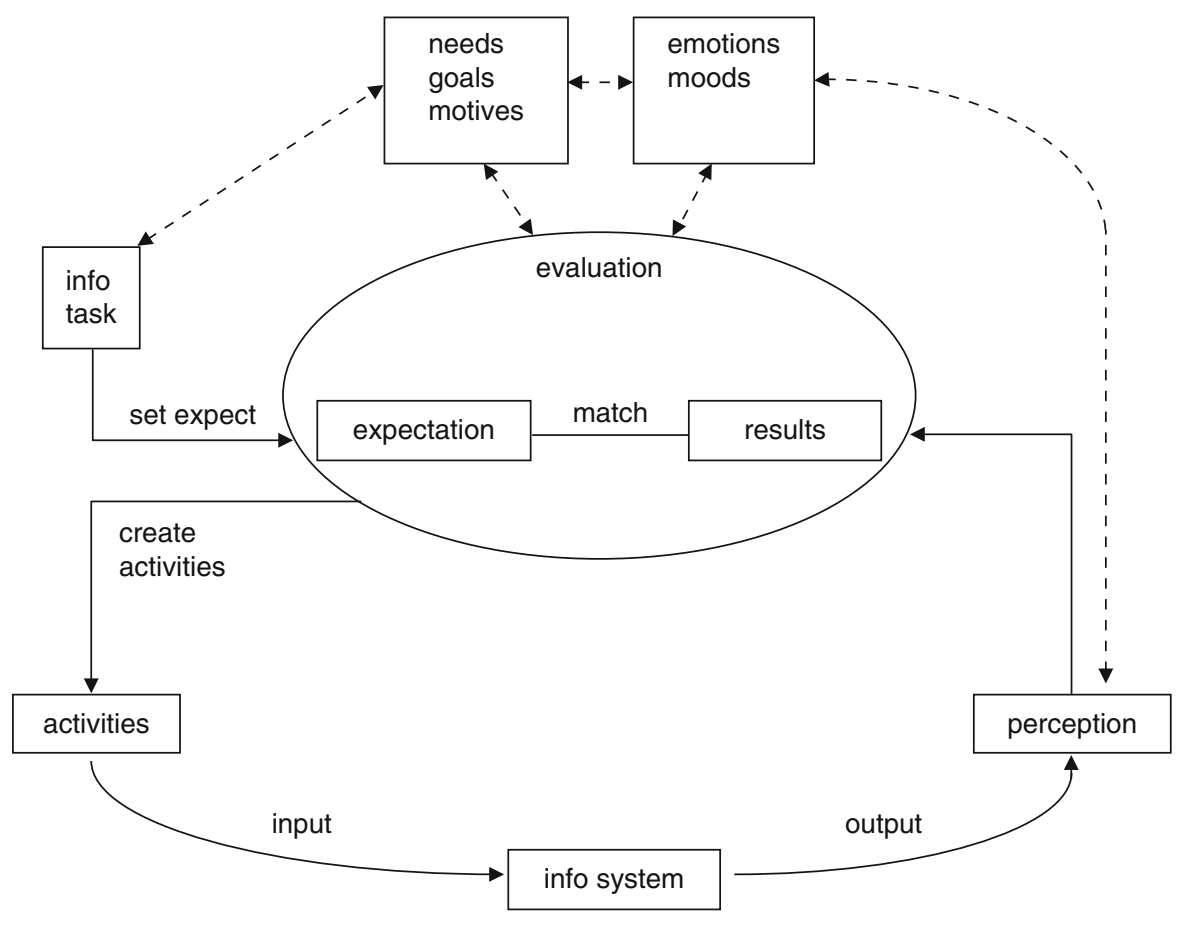

Fig. 18 Model of human-information-system-interaction

aviation sector these so-called habit patterns (stimulus $\mathrm{x}=$ reaction $\mathrm{y}$ ) are trained specifically to enable the safe and constant execution of a certain behaviour also in high-stress situations. This also comprises the access to specific information following certain relevant cues.

However, at this point it is possible that the information task cannot be "accepted" and performed due to prioritization and also due to a reluctance to do so aversion as (emotion). In the aviation sector, for instance, a pilot may experience reluctance if he has already processed a checklist (in an electronic flight bag) repeatedly during several short-distance flights on the same day, thus deciding not to complete the checklist during the next short-distance flight. In addition, decision processes may occur in which the pilot decides not to access an information system since the required period of time for the information to become available is too long and the access thus not beneficial to process control. Furthermore, prioritization may alter during the access to an information system due to system or environmental changes, resulting in the termination of the information search.

The formation of expectations happens as part of the interaction between personal characteristics (abilities and skills, subjective formation of values, etc.), 
information goals (also with regard to accuracy and clarity of information goals), priorities within process control as well as the perceived characteristics of an information system (configuration, information organization, navigational aids, stringency, etc.). On the one hand, expectations are generated by practise, training and application and can be explicit or implicit. They are based on experiences with certain information systems (or information system categories):

- Similar information systems which are applied to the current application,

- The information paths offered by the information system and the operator's own search strategies (duration and also "ease" of the information search),

- Quality, media type (image, text, video, hypermedia etc.) and scope (degree of detail) of information, and

- Practical suitability and context sensitivity of information (with regard to information application).

On the other hand, expectations regarding the configuration and function of an information system may be based on hearsay (e.g. "heard from another driver how complex and difficult it is to use the driver information system of a certain brand") and more or less realistic mental models.

Regardless of whether expectations are based on a realistic model of an information system or information characteristics they establish the basis of an expectation-result appraisal which is made not only at the beginning and at the end of the information system access, but also in iterative steps during the search process.

In the transport sector expectations are broadly diversified on the realistic-vs.unrealistic scale due to the differences regarding professionalism (e.g. average pilot vs. average driver). Pilots are trained to access an information system in the cockpit in type rating training and familiarization. This automatically results in the formation of realistic models and expectations which are generally confirmed automatically in an expectation-result comparison. In contrast, the automobile sector encompasses the total range of professional and unprofessional drivers (wide population distribution). In terms of information system design this results in special requirements for the adaptation of abilities and skills.

If the operator has decided to access an information system he will in a professional environment generally revert to strategies he has learned in order to achieve his intended information goals. These strategies may be well trained search algorithms (navigation, query-based search) or also trial-and-error strategies (browsing, exploration, pattern-based search) if the operator has little experience with the information system. The latter can frequently be observed also in modern flight decks with a high level of automation. This automation complexity (and also information presentation complexity) often exceeds the cognitive resources of the operator.

The achieved information results are initially processed cognitively. This means that they are integrated in existing knowledge, i.e. working memory (in case of high relevance and high probability of repeated use they are stored in the long term memory). Subsequently, the final expectation-result-comparison is initiated.

The required information may not be found promptly or only fragments of the anticipated information may be available or scope and degree of detail may not 
fulfil the expectations of the operator. Thus, cognitive processes subsequently take place during which the operator calculates the usefulness of information for process control vs. costs or time and then decides whether the search for information is continued or discontinued. Furthermore, if information goals are not achieved regulation processes take place during which either information task requirements (requirement level) are reduced or mental effort is increased (mental effort, cf. Sanders 1983; see also action regulation, cf. Herczeg 2009). Greater mental effort on the human energetic level - as described by Sanders (1983) - affects arousal (effectiveness of recognition of stimuli and dealing with stimuli) on the one hand and activation (improvement of motor output) on the other.

It should also be noted that in addition to the goal expectations of the operator environmental or system factors which are partly the basis of "formulated" goal expectations may also change in the course of a search process. This dynamic means that there may be a certain information need at a certain point of time $\mathrm{X}$ during the use of an information system; this need, however, is postponed prior to the completion of the information search and cognitive processing due to a new (more important) information requirement. For this reason, especially aspects of prioritization of information and also goal expectations play a major role for the user. Moreover, it can be assumed that the extent of the scope and quality or the degree of detail of the goal - i.e. the information required - which is known to the user of an information system varies and that this degree of detail can also change with the movement within the information space.

After the conclusion of the comparison described between the expectations formed and the results (or perceived results) achieved these are weighted in terms of emotion. This means that the entire informational process is associated with a feeling of frustration or even anger if for instance the information goal was not achieved. This emotion will determine the probability of access with regard to the next intended access, controlling the motivational processes. If a certain behaviour (information access) is successful in a specific situation this behaviour is repeated as required and also generalized for other situations. If a certain behaviour is not successful and associated with negative emotions the probability of repeated execution is low.

\section{Summary and Conclusions}

Common action regulation models were used initially to develop a model describing Human-Information-System-Interaction. The analysis of the models indicated that the focus is almost exclusively on perceptive and cognitive processes and that other relevant aspects, e.g. emotion and motivation, also workload and effort regulation are only partly or implicitly integrated in these models. To set the theoretical stage for an extended model constructs like situational awareness, workload, fatigue and decision making were presented in context and subsequently integrated in the Human-Information-System-Interaction model. The approach 
consists of cognitive, motivational as well as emotional processes during access to an information system, information search, information access, the decision making process as well as the resulting action (cf. Stein 2008). The background can serve as a basis for the design and configuration of information systems in various areas, in particular to develop a comprehensive focus on the operator side. Furthermore, the model can provide a theoretical framework for ergonomic analyses of information systems and displays. This is of particular significance in all transportation sectors since the development of electronic flight bags or driver information systems, for instance, has been based exclusively on experience and hardly on theoretical principles. However, theoretical principles form the basis of user-centered development and the systematic advancement of these methods. Finally, it should be mentioned that at present, it is difficult to combine and synthesize the theoretical constructs to one superior and empirically validated model (see also Tsang \& Vidulich, 2003). All cognitive aspects exist next to each other while being only valid in combination and common context. Thus, the analysis of construct relations and proven practical significance/predictive power is still purpose of research.

\section{References}

Andersen, P. B. (1997). A theory of computer semiotics. New York: Cambridge University Press. Anderson, J. R. (2000). Learning and memory: An integrated approach (2nd ed.). New York: Wiley.

Atkinson, R. C., \& Shiffrin, R. (1968). Human memory: A proposed system and its control processes. In K. W. Spence \& J. T. Spence (Eds.), The psychology of learning and motivation: Advances in research and theory (Vol. 2). New York: Academic.

Atkinson, R. C., \& Shiffrin, R. M. (1971). The control of short-term memory. Scientific American, $225,82-90$.

Baddeley, A. D. (1999). Essentials of human memory. Hove: Psychology Press.

Billings, C. E. (1997). Aviation automation - The search for a human-centered approach. Hillsdale: Lawrence Erlbaum.

Boff, K. R., \& Lincoln, J. E. (1988). Fatigue: Effect on performance. Engineering data compendium: Human perception and performance. Wright Patterson AFB, Ohio: Harry G. Armstrong Aerospace Medical Research Laboratory.

Card, S. K., Moran, T. P., \& Newell, A. (1983). The psychology of human-computer-interaction. Hillsdale: Lawrence Erlbaum.

Carroll, J. M., \& Olson, J. R. (1988). Mental models in human-computer interaction. In M. Helander (Ed.), Handbook of human computer interaction (pp. 45-65). Amsterdam: Elsevier.

Dunckel, H. (1986). Handlungstheorie. In R. Rexilius \& S. Grubitsch (Eds.), Psychologie Theorien, Methoden und Arbeitsfelder (pp. 533-555). Hamburg: Rowohlt.

Endsley, M. R. (1988). Design and evaluation for situation awareness enhancement. Proceedings of the human factors society 32nd annual meeting, Human Factors Society, Santa Monica, pp. 97-101.

Endsley, M. R. (1995). Toward a theory of situation awareness. Human Factors, 37(1), 32-64.

Endsley, M. R. (2000). Theoretical underpinnings of situational awareness: A critical review. In M. R. Endsley \& D. J. Garland (Eds.), Situation awareness - Analysis and measurement. Mahwah: Lawrence Erlbaum. 
Fairclough, S. H., Tattersall, A. J., \& Houston, K. (2006). Anxiety and performance in the British driving test. Transportation Research Part F: Traffic Psychology and Behaviour, 9, 43-52.

Flemisch, F. O. (2001). Pointillistische Analyse der visuellen und nicht-visuellen Interaktionsressourcen am Beispiel Pilot-Assistenzsystem. Aachen: Shaker Verlag.

Gaillard, A. W. (1993). Comparing the concepts of mental load and stress. Ergonomics, 36(9), 991-1005.

Gollwitzer, P. M. (1996). Das Rubikonmodell der Handlungsphasen. In J. Kuhl \& H. Heckhausen (Eds.), Motivation, volition und handlung (Enzyklopädie der Psychologie: Themenbereich C, Theorie und Forschung: Ser. 4, Motivation und Emotion 4th ed., pp. 531-582). Bern/ Göttingen/Seattle/Toronto: Hogrefe.

Grandjean, D., Sander, D., \& Scherer, K. R. (2008). Conscious emotional experience emerges as a function of multilevel, appraisal-driven response synchronization. Consciousness \& Cognition, $17(2), 484-495$.

Hacker, W. (1978). Allgemeine Arbeits- und Ingenieurpsychologie. Psychische Struktur und Regulation von Arbeitstätigkeiten. Bern: Huber.

Hacker, W. (1986). Arbeitspsychologie. Berlin/Bern/Toronto/New York: Deutscher Verlag der Wissenschaften/Huber.

Hancock, P. A., \& Szalma, J. L. (2008). Performance under stress. In P. A. Hancock \& J. L. Szalma (Eds.), Performance under stress. Aldershot: Ashgate.

Hart, S. G., \& Staveland, L. E. (1988). Development of a multi-dimensional workload rating scale: Results of empirical and theoretical research. In P. A. Hancock \& N. Meshkati (Eds.), Human mental workload (pp. 139-183). Amsterdam: Elsevier.

Hart, S. G., \& Wickens, C. D. (1990). Workload assessment and prediction. In H. R. Booher (Ed.), Manprint. An approach to system integration (pp. 257-296). New York: Van Nostrand Reinhold.

Heckhausen, H. (1989). Motivation und Handeln. Berlin: Springer.

Heckhausen, H., \& Gollwitzer, P. M. (1987). Thought contents and cognitive functioning in motivational versus volitional states of mind. Motivation and Emotion, 11, 101-120.

Heckhausen, J., \& Heckhausen, H. (2008). Motivation and action. New York: Cambridge University Press.

Herczeg, M. (1994). Software-Ergonomie. Bonn: Addison-Wesley.

Herczeg, M. (2000). Sicherheitskritische Mensch-Maschine-Systeme. FOCUS MUL, 17(1), 6-12.

Herczeg, M. (2002). Intention-based supervisory control - Kooperative Mensch-MaschineKommunikation in der Prozessführung. In M. Grandt \& K.-P. Gärnter (Eds.), Situation awareness in der Fahrzeug- und Prozessführung (DGLR-Bericht 2002-04, pp. 29-42). Bonn: Deutsche Gesellschaft für Luft- und Raumfahrt.

Herczeg, M. (2004). Interaktions- und Kommunikationsversagen in Mensch-Maschine-Systemen als Analyse- und Modellierungskonzept zur Verbesserung sicherheitskritischer Technologien. In M. Grandt (Ed.), Verlässlichkeit der Mensch-Maschine-Interaktion (DGLR-Bericht 2004-03, pp. 73-86). Bonn: Deutsche Gesellschaft für Luft- und Raumfahrt.

Herczeg, M. (2006a). Interaktionsdesign. München: Oldenbourg.

Herczeg, M. (2006b). Differenzierung mentaler und konzeptueller Modelle und ihrer Abbildungen als Grundlage für das Cognitive Systems Engineering. In M. Grandt (Ed.), Cognitive Engineering in der Fahrzeug- und Prozessführung (DGLR-Bericht 2006-02, pp. 1-14). Bonn: Deutsche Gesellschaft für Luft- und Raumfahrt.

Herczeg, M. (2006c). Analyse und Gestaltung multimedialer interaktiver Systeme. In U. Konradt, \& B. Zimolong (Hrsg.), Ingenieurpsychologie, Enzyklopädie der Psychologie, Serie III, Band 2, (S. 531-562). Göttingen: Hogrefe Verlag.

Herczeg, M. (2008). Vom Werkzeug zum Medium: Mensch-Maschine-Paradigmen in der Prozessführung. In M. Grandt \& A. Bauch (Eds.), Beiträge der Ergonomie zur MenschSystem-Integration (DGLR-Bericht 2008-04, pp. 1-11). Bonn: Deutsche Gesellschaft für Luft- und Raumfahrt. 
Herczeg, M. (2009). Software-Ergonomie. Theorien, Modelle und Kriterien für gebrauchstaugliche interaktive Computersysteme (3rd ed.). München: Oldenbourg.

Herczeg, M. (2010). Die Rückkehr des Analogen: Interaktive Medien in der Digitalen Prozessführung. In M. Grandt \& A. Bauch (Eds.), Innovative Interaktionstechnologien für Mensch-Maschine-Schnittstellen (pp. 13-28). Bonn: Deutsche Gesellschaft für Luft- und Raumfahrt.

Hockey, G. R. (1986). Changes in operator efficiency as a function of environmental stress, fatigue and circadian rhythms. In K. R. Boff, L. Kaufmann, \& J. P. Thomas (Eds.), Handbook of perception and human performance (Cognitive processes and performance, Vol. II). New York: Wiley.

Immelmann, K., Scherer, K. R., \& Vogel, C. (1988). Psychobiologie. Grundlagen des Verhaltens. Weinheim: Beltz-Verlag.

Johnson, A., \& Proctor, R. W. (2003). Attention: Theory and practice. London: Sage.

Kahneman, D. (1973). Attention and effort. Englewood Cliffs: Prentice Hall.

Lazarus, R. S. (1974). Psychological stress and coping in adaption and illness. International Journal of Psychiatry in Medicine, 5, 321-333.

Lazarus, R., \& Folkman, S. (1984). Stress, appraisal, and coping. New York: Springer.

Miller, G. A. (1956). The magical number seven, plus or minus two: Some limits on our capacity for processing information. Psychological Review, 63(2), 81-97.

Miller, G. A., Galanter, E., \& Pribram, K. H. (1960). Plans and the structure of behavior. New York: Holt, Rinehart \& Winston.

Nake, F. (2001). Das algorithmische Zeichen. In W. Bauknecht, W. Brauer, \& T. Mück (Eds.). Tagungsband der GI/OCG Jahrestagung 2001, Bd. II, (pp. 736-742), Universität Wien.

NATO. (2001). Research and technology organisation. The Human Factors and Medicine Panel (HFM) Research and Study Group 24. RTO-TR-021 NATO Guidelines on Human Engineering Testing and Evaluation. WWW-Document. http://www.rto.nato.int/panel.asp?panel $=\mathrm{HFM} \& \mathrm{O}=$ TITLE\&topic $=$ pubs\&pg $=3 \#$

Navon, D., \& Gopher, D. (1979). On the economy of the human information processing system. Psychological Review, 86, 214-255.

Newell, A., \& Simon, H. (1972). Human problem solving. Englewood Cliffs: Prentice Hall.

Nordwall, B. D. (1995). Military cockpits keep autopilot interface simple. Aviation Week \& Space Technology, 142(6), 54-55.

Norman, D. A. (1986). Cognitive engineering. In D. A. Norman \& S. W. Draper (Eds.), User centered system design (pp. 31-61). Hillsdale: Lawrence Erlbaum.

Norman, D., \& Bobrow, D. (1975). On data-limited and resource-limited processing. Journal of Cognitive Psychology, 7, 44-60.

Nöth, W. (2000). Handbuch der Semiotik. Stuttgart-Weimar: Metzler.

Pinel, J. (1993). Biopsychology (2nd ed.). Allyn and Bacon, Boston.

Rasmussen, J. (1983). Skills, rules, and knowledge; signals, signs, and symbols, and other distinctions in human performance models. IEEE Transactions on Systems, Man, and Cybernetics, SMC-13(3), 257-266.

Rasmussen, J. (1984). Strategies for state identification and diagnosis in supervisory control tasks, and design of computer-based support systems. In W. B. Rouse (Ed.), Advances in manmachine systems research (Vol. 1, pp. 139-193). Greenwich: JAI Press.

Rasmussen, J. (1985a). The role of hierarchical knowledge representation in decision making and system management. IEEE Transactions on Systems, Man, and Cybernetics, SMC-15(2), 234-243.

Rasmussen, J. (1985b). A framework for cognitive task analysis in systems design. Report M-2519, Risø National Laboratory.

Rasmussen, J. (1986). Information processing and human-machine interaction. New York: NorthHolland.

Rasmussen, J., Pejtersen, A. M., \& Goodstein, L. P. (1994). Cognitive systems engineering. New York: Wiley. 
Sanders, A. F. (1983). Towards a model of stress and human performance. Acta Psychologica, 53, 61-67.

Scheffer, D., \& Heckhausen, H. (2008). Trait theories of motivation. In J. Heckhausen \& H. Heckhausen (Eds.), Motivation and action. New York: Cambridge University Press.

Scherer, K. R. (1984). On the nature and function of emotion: A component process approach. In K. R. Scherer \& P. Ekman (Eds.), Approaches to emotion (pp. 293-317). Hillsdale: Erlbaum.

Scherer, K. R. (1990). Theorien und aktuelle Probleme der Emotionspsychologie. In K. R. Scherer (Ed.), Enzyklopädie der Psychologie (C, IV, 3) (Psychologie der Emotion, pp. 1-38). Göttingen: Hogrefe.

Schneider, K., \& Dittrich, W. (1990). Evolution und Funktion von Emotionen. In K. R. Scherer (Ed.), Enzyklopädie der Psychologie, Teilband C/IV/3 (Psychologie der Emotion, pp. 41-114). Göttingen: Hogrefe.

Schneider, K., \& Schmalt, H.-D. (2000). Motivation. Stuttgart: Kohlhammer.

Seitz, D. P., \& Häcker, H. O. (2008). Qualitative befundanalyse des Konstruktes situational awareness - A qualitative analysis. In Bundesministerium der Verteidigung - PSZ III 6 (Ed.), Untersuchungen des Psychologischen Dienstes der Bundeswehr (Jahrgang, Vol. 43). Bonn: Verteidigungsministerium.

Sheridan, T. B. (1987). Supervisory control. In G. Salvendy (Ed.), Handbook of human factors (pp. 1243-1268). New York: Wiley.

Sheridan, T. B. (1988). Task allocation and supervisory control. In M. Helander (Ed.), Handbook of human-computer interaction (pp. 159-173). Amsterdam: Elsevier Science Publishers B.V. (North Holland).

Simon, H. (1981). The sciences of the artificial. Cambridge: MIT Press.

Stein, M. (2002). Entwicklung eines Modells zur Beschreibung des Transferprozesses am Beispiel Arbeitsschutz. In Bundesanstalt für Arbeitsschutz und Arbeitsmedizin (Ed.), Schriftenreihe der Bundesanstalt für Arbeitsschutz und Arbeitsmedizin. Dortmund/Berlin: Wirtschafts-Verlag.

Stein, M. (2008). Informationsergonomie. Ergonomische Analyse, Bewertung und Gestaltung von Informationssystemen. In Bundesanstalt für Arbeitsschutz und Arbeitsmedizin (Hrsg.), Dormund: Druck der Bundesanstalt für Arbeitsschutz und Arbeitsmedizin.

Stein, M., \& Müller, B. H. (2005). Motivation, Emotion und Lernen bei der Nutzung von internetbasierten Informationssystemen. In Gesellschaft für Arbeitswissenschaft (Ed.), Personalmanagement und Arbeitsgestaltung (Bericht zum 51. Kongress der Gesellschaft für Arbeitswissenschaft vom 22.-24. März 2005, pp. 665-668). Dortmund: GfA Press.

Stein, M., Müller, B. H., \& Seiler, K. (2002). Motivationales Erleben bei der Nutzung von internetbasierten Informationssystemen. In R. Trimpop, B. Zimolong, \& A. Kalveram (Eds.), Psychologie der Arbeitssicherheit und Gesundheit - Neue Welten-Alte Welten 11. Workshop "Psychologie der Arbeitssicherheit", Nümbrecht, 2001 (p. 330). Heidelberg: Roland Asanger.

Szalma, J. L., \& Hancock, P. A. (2002). Mental resources and performance under stress. WWW Dokument Verfügbar unter: http://www.mit.ucf.edu/WhitePapers/Resource\%20white\% 20paper.doc.

Treisman, A. M. (1969). Strategies and models of selective attention. Psychological Review, 76, 282-292.

Tsang, P.S. \& Vidulich, M.A. (2003). Principles and Practice of Aviation Psychology. Mahwah, NJ: Lawrence Erlbaum Association.

Vicente, K. J. (1999). Cognitive work analysis. Hillsdale: Lawrence Erlbaum.

Volpert, W. (1974). Handlungsstrukturanalyse als Beitrag zur Qualifikationsforschung. Köln: Pahl-Rugenstein.

von Cranach, M., \& Kalbermatten, U. (1982). Zielgerichtetes Alltagshandeln in der sozialen Interaktion. In W. Hacker et al. (Eds.), Kognitive und motivationale Aspekte der Handlung (pp. 59-75). Bern: Huber.

Waag, W. L., \& Bell, H. H. (1997). Situation assessment and decision making in skilled fighter pilots. In C. E. Zsambok \& G. Klein (Eds.), Naturalistic decision making (pp. 247-254). Mahwah: Lawrence Erlbaum. 
Ware, C. (2000). Information visualization - Perception for design. San Diego: Academic.

Wickens, C. D. (1980). The structure of attentional resources. In R. Nickerson (Ed.), Attention and performance VIII (pp. 239-257). Hillsdale: Erlbaum.

Wickens, C. D. (1984). Processing resources in attention. In R. Parasuraman \& D. R. Davies (Eds.), Varieties of attention (pp. 63-102). New York: Academic.

Wickens, C. D. (2008). Multiple resources and mental workload. Human Factors, 50, 449-455.

Wickens, C. D., \& Hollands, J. G. (2000). Engineering psychology and human performance. Upper Saddle River: Prentice Hall. 